\title{
The relationship between social rank and spatial learning in pheasants, Phasianus colchicus: Cause or consequence?
}

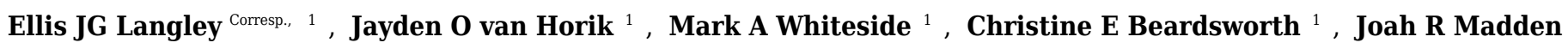

${ }^{1}$ Centre for Research in Animal Behaviour, University of Exeter, Exeter, United Kingdom

Corresponding Author: Ellis JG Langley

Email address: ejg|201@exeter.ac.uk

Individual differences in performances on cognitive tasks have been found to differ according to social rank across multiple species. However, it is not clear whether an individual's cognitive performance is flexible and the result of their current social rank, modulated by social interactions (social state dependent hypothesis), or if it is determined prior to the formation of the social hierarchy and indeed influences an individual's rank (prior attributes hypothesis). We separated these two hypotheses by measuring learning performance of male pheasants, Phasianus colchicus, on a spatial discrimination task as chicks and again as adults. We inferred adult male social rank from observing agonistic interactions while housed in captive multi-male multi-female groups. Learning performance of adult males was assayed after social rank had been standardised; by housing single males with two or four females. We predicted that if cognitive abilities determine social rank formation we would observe: consistency between chick and adult performances on the cognitive task and chick performance would predict adult social rank. We found that learning performances were consistent from chicks to adults for task accuracy, but not for speed of learning and chick learning performances were not related to adult social rank. Therefore, we could not support the prior attributes hypothesis of cognitive abilities aiding social rank formation. Instead, we found that individual differences in learning performances of adults were predicted by the number of females a male was housed with; males housed with four females had higher levels of learning performance than males housed with two females; and their most recent recording of captive social rank, even though learning performance was assayed while males were in a standardized, non-competitive environment. This does not support the hypothesis that direct social pressures are causing the inter-individual variation in learning performances that we observe. Instead, our results suggest that there may be carry-over effects of aggressive social interactions on learning performance. Consequently, whether early life spatial learning performances influence social rank is unclear but these performances are 
modulated by the current social environment and a male's most recent social rank. 
1 THE RELATIONSHIP BETWEEN SOCIAL RANK AND SPATIAL LEARNING IN

2 PHEASANTS, PHASIANUS COLCHICUS: CAUSE OR CONSEQUENCE?

3

4 Ellis J.G. Langley*, Jayden O. van Horik, Mark A. Whiteside, Christine E. Beardsworth, 5 Joah R. Madden

6

7 Centre for Research in Animal Behaviour, Psychology, University of Exeter, EX4 4QG, UK

$8 *$ Correspondence

9 Phone: $+44(0) 1392725122$

10 E-mail: ejg1201@exeter.ac.uk

11 


\section{ABSTRACT}

13 Individual differences in performances on cognitive tasks have been found to differ according to

14 social rank across multiple species. However, it is not clear whether an individual's cognitive

15 performance is flexible and the result of their current social rank, modulated by social interactions

16 (social state dependent hypothesis), or if it is determined prior to the formation of the social

17 hierarchy and indeed influences an individual's rank (prior attributes hypothesis). We separated

18 these two hypotheses by measuring learning performance of male pheasants, Phasianus colchicus,

19 on a spatial discrimination task as chicks and again as adults. We inferred adult male social rank

20 from observing agonistic interactions while housed in captive multi-male multi-female groups.

21 Learning performance of adult males was assayed after social rank had been standardised; by

22 housing single males with two or four females. We predicted that if cognitive abilities determine

23 social rank formation we would observe: consistency between chick and adult performances on

24 the cognitive task and chick performance would predict adult social rank. We found that learning

25 performances were consistent from chicks to adults for task accuracy, but not for speed of learning

26 and chick learning performances were not related to adult social rank. Therefore, we could not

27 support the prior attributes hypothesis of cognitive abilities aiding social rank formation. Instead,

28 we found that individual differences in learning performances of adults were predicted by the

29 number of females a male was housed with; males housed with four females had higher levels of

30 learning performance than males housed with two females; and their most recent recording of

31 captive social rank, even though learning performance was assayed while males were in a

32 standardized, non-competitive environment. This does not support the hypothesis that direct social

33 pressures are causing the inter-individual variation in learning performances that we observe.

34 Instead, our results suggest that there may be carry-over effects of aggressive social interactions

35 on learning performance. Consequently, whether early life cognitive performances determine 
36 social rank requires further investigation but cognitive performances are modulated by the current 37 social environment and a male's most recent social rank. 


\section{INTRODUCTION}

39 To understand how cognitive abilities may have been shaped by natural selection, it is important

40 to characterise the causes and consequences of individual differences in cognitive performances

41 (Thornton, Isden, \& Madden, 2014; Thornton \& Lukas, 2012). An individual's position in a social

42 hierarchy is a critical determinant of an individual's fitness (Von Holst, Hutzelmeyer, Kaetzke,

43 Khaschei, \& Schönheiter, 1999) and is likely to be closely linked to their cognitive performance.

44 Social rank greatly influences their access to resources (Popp \& DeVore, 1979; Wilson, 1975),

45 stress (Abbott et al., 2003; Creel, 2001; Sapolsky, 2005) and opportunities for learning (Chalmeau

$46 \&$ Gallo, 1993). However, it is not clear whether social rank arises as a consequence of pre-existing

47 individual differences in cognitive ability, or if social rank and its associated fitness benefits are a

48 cause of individual differences in cognitive abilities.

49

50 Social rank may be predetermined by individual differences in characteristics that influence social

51 success, as described by the "Prior attributes hypothesis" (Chase et al. 2002). Cognitive ability

52 may be one such characteristic, with cognitively able individuals going on to achieve dominance

53 (Humphrey 1976; Bryne \& Whiten 1988; Seyfarth \& Cheney 2002). For example, behavioural

54 inhibition may enable individuals to respond appropriately to competitors (Amici, Aureli, \& Call,

55 2008) and avoid unnecessary aggression (Strayer, 1976). Social learning can inform individuals

56 about conspecifics motivations (Seyfarth \& Cheney, 2002), as well as their fighting ability and

57 consequently guide future social interactions (fighting fish, Betta splendens, Oliveira, McGregor,

58 \& Latruffe, 1998). Thus, individuals with more proficient social learning abilities have been found

59 to be higher ranking (domestic chickens, Gallus gallus, Nicol \& Pope, 1999). Similarly, we may

60 expect that general learning ability is associated with high social rank (social success, Humphrey, 
61 1976). Learning allows individuals to adapt to changing (social) environments. Performances on 62 operant foraging (starlings, Sturnus vulgaris, Boogert, Reader, \& Laland, 2006) and spatial

63 learning tasks are reported as superior in dominant individuals (pheasants, Phasianus colchicus, 64 Langley et al. 2018; mountain chickadees, Poecile gambeli, Pravosudov et al. 2003; mice, Fitchett 65 et al. 2005; Francia et al. 2006). This may be because individuals that are inherently good at 66 learning are more efficient at beneficial behaviours such as foraging (bumblebees, Bombus 67 terrestris, Raine \& Chittka, 2008), mate choice (Dukas \& Ratcliffe, 2009), and navigating the 68 social environment which brings fitness benefits. However, evidence that these differences in 69 performance existed prior to the establishment of dominance is lacking (Chichinadze, 70 Chichinadze, Gachechiladze, Lazarashvili, \& Nikolaishvili, 2014). There has not been an explicit 71 test of whether individual differences in cognitive performance determine social rank.

73 Alternatively, social rank may be a cause of variation in cognitive performances due to the 74 associated demands of living in a social hierarchy; we term this the 'social-state dependent' 75 hypothesis. This may occur via stress (Abbott et al., 2003; Creel, 2001; Sapolsky, 2005), that arises 76 from the immediate social environment and is influential in shaping the expression of individuals' 77 cognitive ability (De Kloet et al. 1999; Mendl 1999). First, stress may be caused by social pressures 78 and in some cases, the dominant individuals may suffer from high stress and consequently exhibit 79 poorer cognitive performances. When crab-eating macaques, Macaca fascicularis, were placed 80 into different social groups, a natural decrease in rank was accompanied by a decrease in errors on 81 object and colour discrimination and reversal tasks (Bunnell \& Perkins 1980; Bunnell et al. 1980).

82 The authors suggest that the differences in performance between high and low ranking macaques 83 was due to the chronic social stresses experienced by dominant individuals when maintaining their 
84 social rank (Bunnell, Gore, \& Perkins, 1980). Dominant crabs, Chasmagnathus granulatus,

85 demonstrated shorter memory retention of a dangerous signal (context-signal-memory), but only

86 after a dominance encounter, and not before (Kaczer, Pedetta, \& Maldonado, 2007), suggesting

87 that the aggressive encounter was detrimental to the aggressor.

88

89 In some cases, the subordinate individuals may exhibit poorer cognitive performances due to 90 aggression received. The acquisition of dominance status affected spatial learning ability in mice,

91 Mus musculus (Barnard \& Luo, 2002), with the individual of a dyad that became subordinate 92 exhibiting impaired performance. The authors suggest this difference was mediated through

93 aggression as there was a negative relationship between learning performance and the number of 94 aggressive acts received after paired housing. Impairment in subordinate's spatial learning ability 95 also persist in mice, even after previously paired individuals were isolated and social pressures of 96 rank had been removed (Fitchett et al. 2005).

97

98 A second source of stress, resulting from social rank is that of nutritional stress caused by the 99 unequal distribution of resources across a social hierarchy (Wilson 1975; Popp \& DeVore 1979).

100 Dominants are often larger than subordinates (red-deer, Cervus elaphus, Clutton-Brock, Guinness, 101 \& Albon, 1982; carrion crows, Corvus corone corone, Richner, 1989; red-winged blackbirds, 102 Agelaius phoenix, Searcy, 1979) and in many cases more aggressive (Chase et al., 2002), thus 103 winning access to resources. Alternatively, in some species, social rank is maternally inherited and 104 hence relatedness determines access to resources (Japanese macaques, macaca fuscata, 105 Kawamura, 1958). Dominant individuals are reported to be in better body condition than 106 subordinates (great tits, Parus major, Carrascal, Carlos Senar, Mozetich, Uribe, \& Domenech, 
107 1998; red-deer, Clutton-Brock, Albon, \& Guinness, 1984). Improved nutrition may decrease stress

108 overall and additionally dominant individuals may have more energy to invest in costly cognitive 109 abilities (Aiello \& Wheeler, 2009).

110

111 Social rank may influence opportunities for learning and affect cognitive performances.

112 Subordinate chimpanzees, Pan paniscus, were unlikely to interact with a cognitive task when the

113 dominant individual was present (Chalmeau \& Gallo, 1993). In addition to affecting opportunity,

114 social rank may affect the voluntary expression of cognitive ability. Subordinate rhesus macaques,

115 Macaca mulatta, that had previously solved a food choice task, did not express these behaviours

116 in the presence of dominant individuals (Drea \& Wallen, 1999). Consequently, the differences

117 between the social ranks in stress (social and nutritional) and opportunity may each contribute to 118 social rank-related variation in cognitive performances.

119

120 The pheasant, Phasianus colchicus, offers a suitable system in which to explore causality in the

121 relationship between cognitive performances and social rank. Pheasants are a precocial species

122 and large numbers can be hatched on the same day and reared without parents. Pheasant chicks

123 can be assayed for cognitive performance using batteries of psychometric tests under captive

124 conditions (van Horik, Langley, Whiteside, \& Madden, 2016), prior to their release into the wild.

125 Once in the wild, pheasants exhibit harem defense polygyny and males engage in agonistic 126 interactions (Hill \& Robertson 1988). Winners of these interactions are more likely to become 127 dominant territory holders and attract females. Losers of these interactions become satellite males 128 who do not hold fixed territories and are subordinate to territory holders and likely obtain low 129 reproductive success. Territory acquisition begins as early as October (Ridley \& Hill, 1987; 
130 Whiteside et al., 2018) and territory holders have smaller, more concentrated home ranges than 131 subordinate satellite males (Grahn, Goransson, \& von Schantz, 1993). Male pheasants exhibit

132 behavioural indicators of dominance, such as crowing (Ridley \& Hill 1987; Heinz \& Gysel, 1970)

133 and lateral displays (Hill and Robertson 1988), and captive studies demonstrate that dominant

134 males perform these dominance display behaviours at a significantly higher rate than subordinates

135 (Mateos \& Carranza, 1999). These displays are suggested to attract females (Mateos \& Carranza 136 1999) and deter competitors (Hill \& Robertson, 1988; Ridley \& Hill, 1987). In captivity, when

137 males are housed in groups they establish stable hierarchies over short periods at least (Mateos \&

138 Carranza, 1997a, 1997b), and the higher ranking males have preferential access to females and 139 dominate particular areas of the housing aviary (personal observation - EJGL). It is unclear 140 whether captive social hierarchies reflect what occurs in the wild. We have previously shown that 141 variation in performance on a spatial discrimination task is associated with social rank in adult

142 male pheasants, which were tested while housed in a group with an established social hierarchy 143 (Langley et al. 2018). Perhaps, male pheasants that are inherently good at learning about space

144 become dominant because they are better able to recall spatial features and so more efficiently 145 establish and hold a territory. Alternatively, dominant males with smaller home ranges may 146 express better spatial learning performances because they have had more opportunity to learn 147 spatial cues in a reliable and consistent territory (i.e. they learn to learn).

149 We investigated whether the ability to discriminate between locations was a pre-requisite to male 150 pheasants' social rank, or whether this ability is more likely a consequence of social rank. We 151 assayed the cognitive performance of pheasant chicks before we released them into the wild. Then, 152 prior to the breeding season that begins in March and lasts until May (Göransson, von Schantz, 
153 Fröberg, Helgee, \& Wittzell, 1990), we captured adults from the wild. Individuals are captured at 154 this time so that their eggs can be collected for incubation, as part of a larger experiment. We 155 expect that measures of social rank are more meaningful during these months because this is when 156 males are in intense competition for resources, i.e. access to females. We assessed adult males' 157 group social rank while housed in a multi-male multi-female group aviary and also manipulated 158 dominance rank by housing males singly, in a non-competitive, multi-female condition, which we 159 term the 'perceived dominance' condition. Hence, in this condition, males were provided with an 160 uncontested territory, a harem of females and no direct social pressure from other males. While 161 males were in this perceived dominance condition and experiencing equivalent social ranks, we 162 assayed their performance on the same task that we had presented to the chicks. To test whether a 163 male's cognitive performance may be the cause of, or a consequence of social rank, we asked three 164 questions. First, is an individual's cognitive performance consistent from chick to adult? For a 165 cognitive ability to be a prior determinant of social rank, we expected individual cognitive 166 performances to be consistent from chick to adult, as this would indicate cognitive ability 167 developed outside of and prior to dominance interactions. If cognitive performances are not 168 consistent from chick to adult this suggests that they may be altered in response to an individual's 169 current social environment. Second, we asked whether chick cognitive performances predict their 170 future social rank, suggesting that a prior ability in this domain may determine subsequent social 171 rank. Positive results for questions 1 and 2 would provide support for the prior attributes 172 hypothesis. Third, we tested adult males' cognitive performances while they were housed in the 173 perceived dominance condition and investigated whether this was related to their captive social 174 rank. Critically, we assessed whether this perceived dominance condition was associated with 175 increases in "dominance-display" behaviours; crowing and lateral struts, as an indication of the 
176 effectiveness of the rank manipulation. If inter-individual variation in cognitive performance while 177 experiencing this rank manipulation is not explained by an individuals' most recent social rank, 178 this provides support for the social state dependent hypothesis; because all males were 179 experiencing the same social rank and therefore performance on the task is expected to be similar 180 among males. 


\section{METHODS}

182 Study system, subjects \& housing

183 This study was conducted from May 2015-June 2016 at North Wyke Rothamsted Research Farm, 184 Devon $\left(50^{\circ} 77^{\prime} \mathrm{N}, 3^{\circ} 9^{\prime} \mathrm{W}\right)$. We reared 194 pheasant chicks from hatching in one of four identical 185 aviaries. Chicks were identifiable by numbered patagial wing tags (Roxan Ltd). For the first two 186 weeks of life, chicks had access to an indoor $2 \mathrm{~m} \times 2 \mathrm{~m}$ heated aviary. At three weeks they also had 187 access to a covered but unheated $1 \mathrm{~m}$ x $4 \mathrm{~m}$ outdoor run and at four weeks they also had access to a $1884 \mathrm{~m} \times 12 \mathrm{~m}$ outdoor aviary. Throughout the aviaries, chicks had access to perches and food and 189 water ad libitum. Within the indoor section of the aviary, chicks could enter a testing chamber 190 through a sliding door and engage in cognitive testing and exit to the outdoor area via a lift-up 191 door. One hundred and forty-nine chicks participated in the task described in this study. When the 192 chicks were 10 weeks old, we released them on to the site that covers $250 \mathrm{Ha}$ of which there is 193 lowland deciduous woodland, grassland, fen meadow and 40 artificial wheat feeders.

195 In March 2016 we caught adult pheasants ( $\geq 10$ months old) using baited funnel traps. The catching 196 period lasted for three weeks, by the end of which we sighted only two males during field 197 observations, suggesting that we had caught most of the males on the site. We caught 22 males, 19811 of which we had reared as chicks, hereby referred to as known males and the remaining 11 199 males were of unknown rearing history, hereby referred to as unknown males. Known males that 200 we did not catch either died or dispersed off of the site. Adult males were assigned to one of two 201 different outdoor aviaries/social conditions, either; a large group aviary (19 m x $23 \mathrm{~m}$ ), containing 202 multiple females to give a male to female ratio of 60:40; or assigned to one of 10 smaller identical 203 aviaries $(4 \mathrm{~m} \times 8 \mathrm{~m})$, in which males were housed individually with either two or four females. The 
204 allocation of two or four females was determined at random and formed part of a separate 205 experiment on female cognitive performance (Langley et al. accepted). Aviaries were in visual but 206 not auditory isolation from each other. All aviaries contained elevated perches, refuge areas, and 207 food and water ad libitum. Males experienced both social conditions and a general overview of the 208 methods is shown in Figure 1.

209

210

\section{Cognitive test apparatus}

211 Spatial learning and memory tasks on avian subjects typically investigate subjects' ability to 212 reliably locate a food reward on a foraging apparatus containing wells (Western scrub jays, 213 Aphelocoma californica, Pravosudov, Lavenex, \& Omanska, 2005; zebra finch, Taeniopygia 214 guttata, Sanford \& Clayton, 2008; song sparrows, Melospiza melodia, Sewall, Soha, Peters, \& 215 Nowicki, 2013; New Zealand North Island robins, Petroica longpipes, Shaw, Boogert, Clayton, \& 216 Burns, 2015). Wells may be concealed by flaps (Sanford \& Clayton 2008) or filled with sand 217 (Pravosudov et al. 2005), thus requiring the subject to search the locations to retrieve food rewards.

218 Our 'top-bottom' discrimination task required subjects to discriminate between two identical wells 219 arranged vertically on a rectangular apparatus $(38 \mathrm{~cm} \times 14 \mathrm{~cm} \times 4 \mathrm{~cm})$. The top well, furthest from 220 the bird, contained a mealworm food reward. The bottom well, closest to the bird, was unrewarded 221 and blocked by a bung. Both wells were covered with a layer of opaque crepe paper which chicks 222 and adults were trained to peck through prior to testing. Both wells were unmarked and identical 223 and were only distinguishable by their location on the task apparatus (top vs. bottom). During a 224 trial we allowed individuals to make one choice per pair of wells. If individuals chose correctly, 225 indicated by pecking at the crepe paper of the rewarded well, we allowed the individual to consume 226 the food reward before the wells were removed. If individuals chose incorrectly, indicated by 
227 pecking at the crepe paper of the unrewarded well, the wells were removed and a new pair of wells

228 was presented.

229

230 Chick training and cognitive testing

231 From one day old chicks were habituated to human experimenters. We trained chicks to enter a

232 testing arena in groups and allowed them to become familiar with the testing apparatus by placing

233 mealworms in open wells and on top of the apparatus so that they were visible to the chicks. In

234 subsequent training sessions we presented groups of chicks with mealworms only within the wells

235 to encourage individuals to search for rewards within the wells. Following this, we added broken

236 crepe paper onto the wells and over multiple sessions the wells became increasingly concealed

237 until individuals spontaneously pecked through the crepe paper. At approximately three weeks old,

238 chicks were trained to individually enter the testing chamber, located behind a sliding door, upon

239 hearing an auditory command (whistling/humming from a human experimenter). Individuals could

240 voluntarily enter the testing chamber during a training or testing session and the order in which

241 they enter is consistent (van Horik et al., 2016). Cognitive testing began when individuals could

242 competently peck through the crepe paper to retrieve the mealworm reward. Each testing session

243 consisted of 10 trials. Once the trials were completed, chicks were released through the exit door.

244 If a chick displayed signs of stress, such as flapping or lost calling, or they did not interact with

245 the apparatus after two minutes, they were released through the exit door. We tested individuals at

246 eight weeks old for three sessions over two days. There were two morning sessions on consecutive

247 days, beginning at 9am and lasting until approximately 11:30am once all chicks had been tested.

248 Between these two sessions, chicks received one afternoon session beginning at 14:00pm and

249 lasting until approximately $16: 30 \mathrm{pm}$. Food was removed from the aviaries one hour prior to 
250 testing. The three testing sessions resulted in a maximum of 30 trials per individual. Olfactory cues

251 were not controlled for but because galliformes have a poor sense of smell (Corfield et al., 2015),

252 we were confident that individuals were not using olfactory cues to locate the rewarded well.

253

254 Adult social conditions

255 Eleven unknown males and one known male (chosen at random) that we captured as adults were 256 assigned to the 'Social Group (SG)' condition (the large group aviary). The remaining ten known 257 males were assigned to the 'Perceived Dominance (PD)' condition (one of 10 individual aviaries).

258 We housed known males in the same social condition so that we could compare their cognitive 259 performances to their social rank, relative to the other males that they were reared with as a chick.

260 Hence, we did not assign males to the conditions in a randomised way. Due to low participation 261 on cognitive testing from known males while in the PD condition (see below), we also placed 262 unknown males in to the PD condition to assay their learning performance in an attempt to increase 263 our sample size. Hence, males experienced both conditions; those assigned to the SG condition 264 first and then the PD condition are hereby referred to as 'cohort I', and those experiencing the 265 conditions in reverse, are referred to as 'cohort II'.

\section{Social Group (SG) condition}

268 We collected observations ad libitum on the outcomes of dyadic agonistic interactions between 269 males for the inference of social rank (Table 1) and dominance-display behaviours as an indicator 270 of perceived social rank (Table 2). There were two observers at a given time each monitoring

271 different areas of the aviary to ensure all behaviours were recorded. Observers were visually

272 concealed from the birds. For the recording of dyadic agonistic interactions we assigned a winner 
273 and a loser. For the recording of dominance-display behaviours, we calculated rate (event/hour) of

274 each behaviour performed by each male. For cohort I males, observations were collected during

275 weeks $48-53$ on 12 males, prior to cognitive testing in the PD condition (Figure 1). For cohort II

276 males, observations were collected during weeks $54-57$ on 9 males (one male died unexpectedly

277 before being placed in the SG condition), after cognitive testing in the PD condition (Figure 1).

278

279

280

281

282

283

284

285

286

287

288

289

290

291

292

293

294

295

Perceived Dominance (PD) condition

Housing in one of these 10 aviaries provided the male with an exclusive territory, a harem and no direct social pressure from other males. Males were randomly allocated to an aviary containing two or four females. This simulated the male holding a high social rank. Males had their cognitive performance assayed while in this condition only. Outside of cognitive testing we also collected behavioural observations on dominance-display behaviours (Table 2) as an indication of a male's perceived social rank for cohort I males. Dominant males perform these behaviours at a higher rate compared to subordinate males (Mateos \& Carranza 1999). Five of the aviaries could be observed simultaneously and the dominance behaviours were conspicuous. Each day we determined randomly which five aviaries to observe for the first 30 minutes and then observed the remaining five aviaries for 30 minutes. Observations begun at variable times of the day to account for differences between males in their activity levels. For each individual, we calculated rate per hour of each of the two dominance behaviours using the same methods as those used in the SG condition. We did not collect observations on dominance-display behaviours of cohort II males due to time constraints. Adult training and cognitive testing procedures 
296 Performances on the spatial discrimination task were assayed while males were housed in the PD

297 condition. We habituated all individuals to approach the test apparatus, located in the testing area

298 of their aviary (Fig. 2). The apparatus was located between two opaque screens so that it could

299 only be approached and viewed by a bird 'front-on'. These screens were necessary for the testing

300 of adults because the females within the pen were also tested on this task, as part of a separate

301 experiment (Langley, van Horik, Whiteside, \& Madden, 2018b); we wanted to prevent social

302 learning of task affordances and these screens allowed only the bird being tested to view the

303 apparatus. To signal to the males that the apparatus was available, a visual cue (black and white

304 swirl pattern) was placed on the wall in the testing area and we tapped and scratched the apparatus,

305 which was situated in the corner of the aviary. We used similar methods to the chick training

306 regime by heavily baiting the box with mealworms so that they were visible to all birds within the

307 aviary, with the gradual transition to only placing worms within the wells and the addition of crepe

308 paper covering the wells. We attempted to train all 20 males while they were housed in the PD

309 condition, but the males proved difficult to test and appeared distracted by females during the

310 breeding season. We ceased in our attempts to train males that did not interact with the task

311 apparatus on five consecutive training sessions. Three unknown males of cohort I and six known

312 individuals of cohort II reliably participated in the task. During most test sessions, we were

313 required to use a temporary mesh partition that stopped the females from approaching males while

314 they were interacting with the test apparatus. The use of this mesh partition did not appear to be

315 stressful as males readily engaged in cognitive testing shortly after the partition was implemented.

316 Males were not caught or handled during testing. Each testing session consisted of 20 trials and

317 begun between $8 \mathrm{am}$ to $5 \mathrm{pm}$. We chose the order in which to test males at random. If a male did

318 not engage with the task within 10 minutes, we moved on to another male and tried the initial male 
319 later that day and did not repeat the same order of testing on any other day. Individuals received 320 one session per day, for five days, resulting in 100 trials in total. We suspected that this high

321 number of trials would provide us with more detailed learning curves and increase our ability to 322 detect differences between males of different social rank in the rate of learning. We did not include

323 the order of testing in analyses due to small sample size and this variable not being of interest.

324 However, because the task was voluntary, we suspect that once males begun the task, they were 325 equally motivated to engage in testing. Due to adverse weather conditions, cognitive testing for

326 Cohort II was delayed and we ran out of time to replicate this duration for Cohort I; Cohort I and

327 II were housed in the PD condition for 11 and 23 days, respectively, before cognitive testing begun. 328

329 Statistical analysis

330 All analyses were conducted using R v.3.3.3 (The R Foundation for Statistical Computing 2017). Social rank

333 For each cohort we inferred the social hierarchy using the same methods as those in Langley et al. 334 (2018) using the winner-loser data of agonistic and submissive interactions (Table 1), we generated 'Randomized Elo-ratings' using the aniDom package (Farine \& Sanchez-Tojar, 2017) and assessed hierarchy uncertainty using the two methods described in Sanchez-Tojar et al. (2017).

337 First, we estimated repeatability of the individual Elo-ratings generated from replicated datasets $338(\mathrm{n}=1000)$ using the $r p t R$ package (Schielzeth, Stoffel, \& Nakagawa, 2017), with high repeatability 339 scores indicating a steep hierarchy (high probability that a dominant individual wins a contest).

340 Second, we split the interaction dataset into two halves, computed 1000 individual ranks for each

341 half using the randomized Elo-rating method and calculated the Spearman's Rank Correlation $r_{S}$ 
342 between the ratings generated by the two halves. We report the mean $r_{S}$ and $95 \%$ confidence

343 interval range of the correlation values. These results indicated high levels of certainty in the data,

344 therefore we used the mean of the randomized Elo-ratings from the full dataset in subsequent

345 analyses, hereby referred to as 'mean Elo-rating'.

346

347

Cognitive performance

348 We generated learning curves using a binary logistic regression model (GLM) for each individual

349 that performed the top-bottom discrimination task as a chick and as an adult $(n=6)$, using the first

35020 trials for both chicks and adults so that learning curves were comparable. From these curves we

351 calculated the probability that an individual would choose correctly on their final trial ( $\mathrm{X}=\mathrm{Final})$,

352 which is derived from solving the equation $Y=1 /\left(1+\exp \left[-\left(b_{0}+b_{1} X\right)\right]\right)$, whereby $b_{0}$ depicts the

353 intercept and $b_{1}$ depicts the slope estimate from the learning curve GLM. We consider this measure

354 indicative of how well an individual has learned the task by the end of the testing. We also 355 calculated the predicted trial number when an individual reaches or will reach a learning criterion 356 of $80 \%$ probability of choosing correctly $(\mathrm{Y}=80)$, this is derived by solving the equation $X=(-$

$\left.357 \ln 0.25-b_{0}\right) / b_{1}$. We consider this indicative of how much experience an individual requires to

358 adequately learn the affordances of the task. The $\mathrm{X}=$ Final and $\mathrm{Y}=80$ measures were calculated for

359 both chick and adult task performances. We asked three questions to distinguish between

360 directionality in the relationship between cognitive performances and social rank. 1) We tested

361 whether individual learning performances were consistent from chick to adult, using the $I C C$

362 package (Wolak, Fairbairn, \& Paulsen, 2012) to assess the intra-class correlation between chick

363 and adult $\mathrm{X}=$ Final; and chick and adult $\mathrm{Y}=80$. This was conducted on six individuals that

364 completed the task at both ages. 2) We tested whether chick learning performance predicted adult 
365 social rank using a Spearman's Rank Correlation between chick X=Final and their adult mean Elo-

366 rating; and chick $Y=80$ and their adult mean Elo-rating. This was conducted on one individual of

367 cohort I and seven individuals of cohort II, that completed the cognitive task as a chick (two

368 additional individuals to those in question 1; that did not complete adult cognitive testing). 3)

369 Finally, we fit a generalized linear mixed model (GLMM) with a binomial error structure and a

370 logit link function to assess whether adult learning performance (correct: 1 yes / 0 no) was

371 predicted by group social rank (mean Elo-ratings). We also included cohort, the number of females

372 that males were housed with during the PD condition, choice on first trial (correct: 1 yes / 0 no)

373 and trial number (2-100) as explanatory variables. A two-way interaction between mean Elo-rating

374 and trial number was included to examine whether individuals differ in their rate of learning in

375 relation to their group social rank. We define rate of learning as the speed at which individuals

376 switch from making a series of incorrect choices to a series of correct choices and is deduced from

377 the steepness of the learning slope (trial* social rank; $b_{1}$ ). A main effect of trial is indicative that

378 there was an increase in the probability that males would choose correctly as trial number

379 increased. A main effect of social rank on learning performance is indicative that social ranks

380 differ in their overall accuracy of task performance, inclusive of performance on all trials. We

381 included cohort to account for the order in which males experienced the social conditions, as well

382 as their rearing history (i.e. whether they had experienced this task as a chick). We included the

383 number of females in the PD condition because we have previously shown that group size affects

384 female learning performance (Langley et al., 2018b). We included choice on first trial (correct: 1

385 yes / 0 no) to control for random choice on this first trial; as this trial was prior to the opportunity

386 for learning but may affect subsequent performance on the task and this left the trial variable with

387 trial number $2-100$ (after trial 1 was removed). To facilitate convergence we converted trial 
388 number and mean Elo-ratings to z-scores (Gelman and Hill 2007). Individual was included as a

389 random term (random intercepts, fixed slopes model). We assessed the fit of this model by 390 comparing it to an equivalent random intercepts and random slopes model and found that the 391 random intercepts only model was adequate $\left(X^{2}=0.261, p=0.878\right)$ and therefore used this for

392 subsequent analyses. We tested the significance of explanatory variables using likelihood ratio 393 tests. This model was fitted on eight adult males that each completed 100 trials; 3 males of cohort 394 I and five males of cohort II.

395

396

Dominance display behaviours

397 We investigated the effectiveness of our rank manipulation and compared rates of dominance398 display behaviours of males when they were in the SG condition with the rates of dominance399 display behaviour when they were housed in the PD condition, using a Wilcoxon signed-ranks test 400 on all 10 individuals of cohort I. We adjusted the rate of lateral displays directed towards females 401 by controlling for female density by dividing the mean rate of displays performed by the number 402 of females housed in the aviary. We only included lateral struts which were directed towards 403 females so this was consistent between social conditions (females are present in both social 404 conditions, whereas multiple males were only present in the SG condition and we wanted to avoid 405 introducing bias into our results); lateral displays that were clearly directed towards males or in 406 cases where the receiver was ambiguous, were not included in analyses.

407

408 Ethical considerations

409 Chicks and adults were habituated to human observation and were subject to minimal handling.

410 All training procedures were adopted to mitigate stress during cognitive testing and birds could 
411 choose whether or not to participate in tasks. Experimenters were concealed from view of the birds 412 and birds were reared at a lower density than that recommended by DEFRA's code of practice 413 (DEFRA, 2009), thus reducing stress. During capture of adults from the wild, traps were checked 414 at least three times a day. Adult birds were held in captivity for three months, after which they 415 were released at the capture site. All work was approved by the University of Exeter Psychology 416 Ethics Committee and the work was conducted under Home Office licence number PPL 30/3204 417 to JRM. 


\section{RESULTS}

419 i. Is learning performance consistent from chick to adult?

420 Consistency in chick and adult learning performances after 20 trials on the spatial discrimination

421 task was significantly different from zero (Intra-class correlation coefficient $=0.464 ; 95 \%$

422 confidence interval: $0.373-0.900$; Figure 3 ). Conversely, the consistency in chick and adult

423 learning performances in the predicted trial number of having reached a learning criterion of $80 \%$

424 was not significantly different from zero (intra-class correlation coefficient $=-0.244 ; 95 \%$

425 confidence interval: $-0.816-0.618$; Figure 4). This suggests that individuals are consistent in their

426 accuracy after 20 trials but differ in their predicted number of trials taken to reach a learning

427 criterion.

428

429 ii. Does a chick's learning performance predict adult social rank?

430 The two uncertainty measures we obtained from using the Randomized Elo-rating method to 431 generate hierarchies for both cohorts, indicate these inferred hierarchies were highly reliable 432 indicators of social rank (Table 3). We found no relationship between mean Elo-rating and chicks' 433 predicted performances at the end of the spatial discrimination task (Spearman's Rank Correlation: $434 \mathrm{X}=$ Final, $\left.r_{s}=0, n=8, p=0.99\right)$. Similarly, there was no relationship between the trial number in 435 which chicks were predicted to reach an $80 \%$ probability of choosing correctly and their adult 436 social rank (Spearman's Rank Correlation: $\left.\mathrm{Y}=80, r_{s}=-0.524, n=8, p=0.197\right)$.

437

iii. Does variation in cognitive performances persist once social rank is standardised? Evidence that the social rank manipulation was effective 
440 Both indicators of dominance (crowing and lateral displays) were expressed at higher rates by

441 males in single male groups than when housed in social groups. Of the ten males of cohort I, two

442 males never crowed in either social condition and eight males increased their rate of crowing

443 behaviour while housed in the rank manipulation (PD condition) compared with when they were

444 housed in the social group (SG condition) (Wilcoxon Signed Ranks test: $n=10, p=0.014$, Table

445 4, Fig. 5).

446

447 Three of ten males performed fewer lateral struts while in the PD condition compared with when

448 they were housed in the SG condition, whereas seven males performed struts at a higher rate while

449 housed in the PD condition (Wilcoxon Signed Ranks test: $n=10, p=0.002$, Table 4, Fig. 6).

450

451

Cognitive performance during a rank manipulation

452 While adult males were housed in the perceived dominance condition (PD), individuals that had a

453 high social rank when in the social group (SG) condition, learned the spatial discriminations at a

454 faster rate than those of lower social rank (GLMM: Trial number*mean Elo-rating, $X^{2}=12.143$,

$455 d f=1, p<0.001$, Table 5, Fig. 7). The number of females a male was housed with during the PD

456 condition was a significant predictor of spatial discrimination task performances (GLMM: number

457 of females, $X^{2}=11.255, d f=1, p<0.001$ ), with males housed with four females having a higher

458 probability of choosing correctly than males housed with two females (Table 5). High and low

459 ranking males were equally as likely to be housed with four females (Table 6). Whether males

460 were known or unknown did not relate to learning performances and this variable also controlled

461 for the order in which the males experienced the two different social conditions (GLMM: cohort,

$\left.462 X^{2}=0.554, d f=1, p=0.456\right)$. Whether a male chose correctly on their first trial did not relate to 
463 performance on the remainder of the task (GLMM: first choice, $X^{2}=1.187, \mathrm{df}=1, \mathrm{p} 0.276$ ) and 464 males across the hierarchy were equally as likely to choose correctly or incorrectly on their first 465 choice (Table 6).

466 


\section{DISCUSSION}

468 The relationship between cognitive performance and social rank is often reported but the issue of 469 whether performance on a cognitive task is a cause or consequence of social rank is seldom 470 considered. We show that cognitive performances on a spatial discrimination task by male 471 pheasants were partly consistent across an individual's lifetime but that chicks' performances 472 failed to predict their adult social rank. Therefore, we cannot conclude that adult social rank is a 473 consequence of a male's spatial learning performance. However, when we manipulated social rank 474 so that all males experienced conditions synonymous with high dominance rank (uncontested 475 territory and access to females), we found that a male's learning performance continued to be 476 predicted by their captive social rank, even when this social rank was recorded after cognitive 477 testing. Additionally, the number of females that single males were housed with during the rank 478 manipulation also predicted cognitive performances, with males accompanied by larger groups of 479 females exhibiting higher probabilities of making correct choices. Our findings do not allow us to 480 decipher cause and consequence of the relationship but suggest that spatial learning performances 481 and social rank may become associated over time and the relationship persists even when the direct 482 social pressures associated with social rank have been removed.

484 The prior attributes hypothesis describes that a high correlation coefficient between an attribute 485 and social rank, is indicative of that attribute having assisted in rank formation (Chase, 1974). This 486 hypothesis originally focused on morphological attributes that were developed prior to the 487 formation of the hierarchy but were measured while the dominance hierarchy is established and 488 active, with the inference that these traits assisted in the establishment of the dominance hierarchy.

489 Cognitive performances have been suggested to determine social success (Byrne \& Whiten, 1988; 
490 Call, 2001; Cheney, Seyfarth, \& Smuts, 1986; Dunbar, 1998; Humphrey, 1976; Seyfarth \&

491 Cheney, 2002; Taborsky \& Oliveira, 2012). However, testing whether cognitive performances can

492 predict social rank at the individual level is difficult, and to date, this has not been shown

493 (Chinchinadze et al. 2014). For cognitive or behavioural attributes, which are highly plastic,

494 measures must be collected prior to the formation of the hierarchy to avoid the confounding

495 possibility that the expression of the attribute is simply a result of social rank. Dominant

496 individuals outperform subordinate individuals on spatial learning tasks (Barnard \& Luo, 2002;

497 Fitchett et al., 2005; Francia et al., 2006; Langley, van Horik, Whiteside, \& Madden, 2018a;

498 Spritzer, Meikle, \& Solomon, 2004). If the ability to discriminate between spatial cues early in life

499 is beneficial to determining social rank in pheasants, then we expected that cognitive performance

500 of chicks would predict adult cognitive performance and their future social rank. Generally, our

501 findings do not support this. Although there was consistency between chick and adult cognitive

502 performances in their task accuracy, thus suggesting that this ability is fixed across an individual's

503 lifespan and could determine social rank, individuals' 'speed' to reach a learning criterion was not

504 consistent. Furthermore, chick cognitive performances did not predict their estimated social rank

505 as adults. We emphasise that our sample size was small and the results should be interpreted with

506 caution, but if this is a general pattern we suggest two interpretations of these findings.

507

508 Spatial learning ability may be subject to cognitive development (Nowicki, Searcy, \& Peters, 509 2002) and influenced by experience (Rowe \& Healy, 2014) in the wild. Thus, learning 510 performances assayed during early life while individuals were housed in controlled and identical 511 conditions may not be representative of learning performances that influence a male's ability to 512 attain/maintain a particular social rank as an adult, i.e. spatial learning performances may predict 
513 social rank but are not necessarily consistent across an individual's life. Further testing of spatial

514 learning abilities at various life stages and at which point they predict social rank are required to

515 better understand this relationship.

\section{6}

517 Alternatively, the ability to discriminate between two locations in a food-motivated task in early

518 life capture realistic processes and skills that are not influential in attaining a high social rank.

519 Although high levels of aggression are associated with superior spatial learning performances in

520 adult animals (pheasants, Langley et al. 2018; mice, Francia et al., 2006; meadow voles, Spritzer,

521 Meikle, \& Solomon, 2004; mountain chickadees, Pravosudov et al., 2003), spatial learning

522 performances early in life may not correspond to future social interactions involved with hierarchy

523 formation. If learning performances do influence social rank but learning in the spatial domain is

524 unrelated to learning performances in other domains (domain-specific cognition, Shettleworth,

525 2010), then performances during early life on tasks assaying other cognitive domains may better

526 predict an individual's future social rank. For example, social learning abilities which inform

527 individuals' partner choices and the outcome of social interactions (fighting fish, Oliveira et al.,

528 1998) may better predict social rank. The lack of a relationship between early life spatial learning

529 performances and adult social rank may suggest that the relationship we observe in the adults is

530 driven by the influence of aggression on spatial learning performances, rather than the reverse.

531

532 We also attempted to address whether the relationship between spatial learning performance and

533 social rank in adults is as a result of current social rank. Our findings offer some support that the

534 current social environment causes individual variation in cognitive performances. Inter-individual

535 variation in learning performance was affected by the number of females a male was housed with 
536 during cognitive testing. Males housed with four females had a higher probability of choosing

537 correctly than males housed with only two females. The mechanisms behind this effect are

538 unknown (see Langley et al. 2018b), but this suggests that the current social environment has direct

539 influences on individual variation in cognitive performances.

540

541 Further indication that the social environment influences variation in cognitive performances, 542 comes from the comparison between this study and Langley et al. (2018a). Langley et al. (2018a)

543 found that higher ranking males demonstrated greater learning accuracy but did not learn at a faster 544 rate than lower ranking males. In the current study, more dominant males learned spatial

545 discriminations at a faster rate than lower ranking males; shown by the significant interaction

546 between trial number and social rank. The subtle differences between the two studies may be due

547 to the differences in the social conditions experienced while cognitive performance was assayed.

548 Langley et al. (2018a) assayed cognitive performance while males were living in a social hierarchy

549 and under direct pressures of maintaining and acquiring resources. In this study, cognitive

550 performance was assayed while males were not experiencing direct social pressure from other

551 males. This suggests that the rate of learning differs between males of different social rank only

552 when males are tested away from the direct pressures of the social hierarchy. Alternatively, such

553 differences may be due to the different tasks used. Langley et al. (2018a) investigated learning

554 performance in an escape-type task, as opposed to the food motivated learning task used in this

555 study. Investigating the relationship between learning performances and social rank using different

556 cognitive tasks will be useful in elucidating whether social interactions are more strongly related

557 to certain cognitive performances, more so than others. Finally, differences between the two

558 studies may have arisen because of a difference in the number of trials that were conducted; here 
559 we conducted 100 trials which gives us much stronger statistical power when determining rate of

560 learning. To further understand the effects of social rank on spatial learning performances,

561 repeatedly testing individuals while experiencing different social environments (social hierarchy

562 and manipulated social rank), on cognitive tasks targeting the same cognitive domain with the

563 same task affordances, may be one such approach.

564

565 In previous studies supporting the social-state dependent hypothesis, acquisition of social rank

566 (mice, Barnard \& Luo 2002) or a natural rank change (crab-eating macaques, Bunnell et al. 1980),

567 influenced changes in individual learning performances. In these cases, social rank was not

568 manipulated. Our finding that variation in performance on a learning task corresponds to rank even

569 following a rank manipulation, indicates that the relationship between social rank and cognitive

570 performance is not necessarily driven by current stressors of living in a social hierarchy. We

571 suggest three explanations for these findings in adults.

572

573 First, the effects of social rank on cognitive performances may persist even when the immediate

574 social setting has changed. The effects of social defeat/success on performance on a spatial

575 learning task in mice were found to persist up to 13 weeks after social pressures had been removed

576 and mice were housed individually (Fitchett et al. 2005). Pheasants agonistic and submissive

577 interactions in the wild may have contributed to variation in cognitive performances. If carry-over

578 effects of past social interactions are driving inter-individual differences in learning, the time it

579 takes for these differences in learning performance to diminish may also give an indication of how

580 long the effects of social defeat, or success, persist (Laskowski et al. 2016; Hsu, Earley, \& Wolf,

581 2006). Further, the relationship between cognitive performances and social rank was observed 
582 regardless of whether social ranking was scored before cognitive testing or afterwards. This

583 suggests that individuals are consistent in their social rank experienced in the wild and in captivity.

584

585 Second, the relationship between social rank and spatial learning may be mediated by a third 586 variable that we did not measure or modify. For example, individuals suffering from high parasite 587 load may not only have their cognitive performance affected (bumblebees, Bombus impatiens, 588 Gegear, Otterstatter, \& Thomson, 2005), but also be unable to obtain high social rank (red jungle 589 fowl, Gallus gallus, Zuk, Kim, Robinson, \& Johnsen, 1998). Future studies may benefit from 590 manipulating parasite load to examine whether these are contributing factors of performances on 591 cognitive tasks and the outcomes of social interactions.

592

593 Third, social-rank-related variation in spatial learning performances may have been evident even 594 while individuals were isolated from other males because the manipulation of social rank was not 595 as successful as we believed. Although we observed increases in dominance behaviours (crowing 596 and lateral struts) from singly housed males, the males were still in auditory communication with 597 neighbouring males. Crowing is a behaviour performed by dominant males and may act to indicate 598 territory ownership to conspecifics (Heinz \& Gysel 1970; Ridley 1987). It is possible that male 599 crows communicate dominance status to conspecifics and males were able to assess their relative 600 rank through neighbouring males' crows and so maintain some form of perceived hierarchy even 601 when housed away from direct social contact. To our knowledge, the specific information that 602 pheasant crows communicate has not been formally tested.

603

604 Conclusion 
605 Performance on a spatial discrimination task during early life does not convincingly predict 606 performance on the same task in adulthood, nor does it predict adult social rank in male pheasants, 607 so we conclude that the ability to discriminate between locations may be flexible across an 608 individual's life and does not necessarily provide an advantage in acquiring a high social rank. 609 Instead, when adult, an individual's spatial learning performance does relate to their position in a 610 social hierarchy, and this variation exists even when direct contests with other males are prevented.

611 We also demonstrate that the number of females accompanying a male, affects the spatial learning 612 performance of males. These two results indicate that the social environment, past and current, 613 explains variation in spatial performances. An individual's cognitive performance is unlikely to be 614 fixed from early life, but rather may develop over their lifespan, possibly mediated by their social 615 interactions, and even in mature adults retain some level of plasticity depending on their immediate 616 social conditions. It remains unclear to what extent spatial learning performance and social rank 617 are causally linked. 


\section{ACKNOWLEDGEMENTS}

619 We thank Rothamsted Research North Wyke for accommodating the rearing and release of the

620 pheasants. We are grateful to Pip Laker, Rachel Peden and Kenzie Bess for help with husbandry

621 and data collection. We thank Tim Fawcett for providing statistical advice. We thank the editor

622 and three anonymous reviewers for their help in improving the manuscript. 


\section{REFERENCES}

624

625

626

627

628

629

630

631

632

633

634

635

636

637

638

639

640

641

642

643

644

645

646

647

648

649

650

651

652

653

654

655

656

657

658

659

660

661

662

663

664

665

666

667
Abbott, D. H., Keverne, E. B., Bercovitch, F. B., Shively, C. A., Mendoza, S. P., Saltzman, W., Sapolsky, R. M. (2003). Are subordinates always stressed? a comparative analysis of rank differences in cortisol levels among primates. Hormones and Behavior, 43(1), 67-82. http://doi.org/10.1016/S0018-506X(02)00037-5

Aiello, L. C., \& Wheeler, P. (2009). The Expensive-Tissue Hypothesis: The Brain and the Digestive System in Human and Primate Evolution. Current Anthropology, 36(2), 199-221. https://doi.org/10.1086/204350

Amici, F., Aureli, F., \& Call, J. (2008). Fission-fusion dynamics, behavioral flexibility, and inhibitory control in primates. Current Biology : CB, 18(18), 1415-9. http://doi.org/10.1016/j.cub.2008.08.020

Barnard, C. J., \& Luo, N. (2002). Acquisition of dominance status affects maze learning in mice. Behavioural Processes, 60, 53-59. http://doi.org/10.1016/S0376-6357(02)00121-3

Boogert, N. J., Reader, S. M., \& Laland, K. N. (2006). The relation between social rank, neophobia and individual learning in starlings. Animal Behaviour, 72(6), 1229-1239. http://doi.org/10.1016/j.anbehav.2006.02.021

Bunnell, B. N., Gore, W. T., \& Perkins, M. N. (1980). Performance correlates of social behavior and organization: Social rank and reversal learning in crab-eating macaques $(M$. fascicularis). Primates, 21(October), 376-388. http://doi.org/10.1007/BF02373840

Byrne, R. W., \& Whiten, A. (1988). Machiavellian Intelligence: Social Expertise and the Evolution of Intellect in Monkeys, Apes and Humans. Oxford: Oxford University Press.

Call, J. (2001). Chimpanzee social cognition. Trends in Cognitive Sciences, 5(9), 388-393. http://doi.org/10.1016/S1364-6613(00)01728-9

Carrascal, L. M., Carlos Senar, J., Mozetich, I., Uribe, F., \& Domenech, J. (1998). Interactions among Environmental Stress, Body Condition, Nutritional Status, and Dominance in Great Tits. The Auk, 115(3), 727-738. http://www.jstor.org/stable/4089420

Chalmeau, R., \& Gallo, a. (1993). Social constraints determine what is learned in the chimpanzee. Behavioural Processes, 28, 173-179. http://doi.org/10.1016/03766357(93)90090-E

Chase, I. D. (1974). Hierarchy formation in animal societies'. Behavioural Science, 19, 374-382. https://doi.org/10.1002/bs.3830190604

Chase, I. D., Tovey, C., Spangler-Martin, D., \& Manfredonia, M. (2002). Individual differences versus social dynamics in the formation of animal dominance hierarchies. Proceedings of the National Academy of Sciences of the United States of America, 99(8), 5744-5749. http://doi.org/10.1073/pnas.082104199

Cheney, D. L., Seyfarth, R. M., \& Smuts, B. (1986). Social Relationships and Social Cognition and Nonhuman Primates. http://doi.org/10.1016/j.exger.2009.02.008.Metabolic

Chichinadze, K., Chichinadze, N., Gachechiladze, L., Lazarashvili, A., \& Nikolaishvili, M. (2014). Physical predictors, behavioural/emotional attributes and neurochemical determinants of dominant behaviour. Biological Reviews, 89, 1005-1020. http://doi.org/10.1111/brv.12091

Clutton-Brock, T. H., Albon, S. D., \& Guinness, F. E. (1984). Maternal dominance, breeding success and birth sex ratios in red deer. Nature, 308(5957), 358-360. http://doi.org/10.1038/308358a0

Clutton-Brock, T. H., Guinness, F. E., \& Albon, S. D. (1982). Red deer: Behavior and ecology of 
668

669

670

671

672

673

674

675

676

677

678

679

680

681

682

683

684

685

686

687

688

689

690

691

692

693

694

695

696

697

698

699

700

701

702

703

704

705

706

707

708

709

710

711

712

713

two sexes. University of Chicago Press.

Corfield, J. R., Price, K., Iwaniuk, A. N., Gutierrez-IbaÃ \pm ez, C., Birkhead, T., \& Wylie, D. R. (2015). Diversity in olfactory bulb size in birds reflects allometry, ecology, and phylogeny. Frontiers in Neuroanatomy, 9(July), 1-16. http://doi.org/10.3389/fnana.2015.00102

Creel, S. R. (2001). Social dominance and stress hormones. Trends in Ecology \& Evolution, 16(9), 491-497. https://doi.org/10.1111/j.1523-1739.2001.99534.x.

Drea, C. M., \& Wallen, K. (1999). Low-status monkeys "play dumb" when learning in mixed social groups. Proceedings of the National Academy of Sciences of the United States of America, 96(22), 12965-9. https://doi.org/10.1073/pnas.96.22.12965.

Dukas, R., \& Ratcliffe, J. M. (2009). Cognitive ecology (II). Chicago: University of Chicago Press.

Dunbar, R. I. M. (1998). The Social Brain Hypothesis. Evolutionary Anthropology: Issues, News, and Reviews, 6(5), 178-190. http://doi.org/10.1002/(SICI)1520-6505(1998)6:5<178::AIDEVAN5>3.3.CO;2-P

Farine, D. R., \& Sanchez-Tojar, A. (2017). aniDom: Inferring Dominance Hierarchies and Estimating Uncertainty. https://cran.r-project.org/package=aniDom

Fitchett, A. E., Collins, S. A., Barnard, C. J., \& Cassaday, H. J. (2005). Subordinate male mice show long-lasting differences in spatial learning that persist when housed alone. Neurobiology of Learning and Memory, 84(3), 247-251. http://doi.org/10.1016/j.nlm.2005.08.004

Francia, N., Cirulli, F., Chiarotti, F., Antonelli, A., Aloe, L., \& Alleva, E. (2006). Spatial memory deficits in middle-aged mice correlate with lower exploratory activity and a subordinate status: Role of hippocampal neurotrophins. European Journal of Neuroscience, 23(3), 711-728. http://doi.org/10.1111/j.1460-9568.2006.04585.x

Gegear, R. J., Otterstatter, M. C., \& Thomson, J. D. (2005). Does parasitic infection impair the ability of bumblebees to learn flower-handling techniques? Animal Behaviour, 70(1), 209 215. http://doi.org/10.1016/j.anbehav.2004.09.025

Göransson, G., von Schantz, T., Fröberg, I., Helgee, A., \& Wittzell, H. (1990). Male characteristics, viability and harem size in the pheasant, Phasianus colchicus. Animal Behaviour, 40(1), 89-104. http://doi.org/10.1016/S0003-3472(05)80668-2

Grahn, M., Goransson, G., \& von Schantz, T. (1993). Spacing behaviour of male pheasants, Phasianus colchicus, in relation to dominance and mate acquisition. Animal Behaviour, 45, 93-103.

Heinz, G. H., \& Gysel, L. W. (1970). Vocalization behavior of the ring-necked pheasant. The Auk, 87, 279-295.

Hill, D. \& Robertson, P. (1988). The Pheasant: Ecology, Management and Conservation. Kent: BSP Professional Books.

Hsu, Y., Earley, R. L., \& Wolf, L. L. (2006). Modulation of aggressive behaviour by fighting experience: mechanisms and contest outcomes. Biological Reviews of the Cambridge Philosophical Society, 81, 33-74. http://doi.org/10.1017/S146479310500686X

Humphrey, N. K. (1976). The social function of intellect. (P. P. . Bateson \& R. . Hinde, Eds.) Growing Points in Ethology. Cambridge: Cambridge University Press. http://doi.org/10.2307/375925

Kaczer, L., Pedetta, S., \& Maldonado, H. (2007). Aggressiveness and memory: Subordinate crabs present higher memory ability than dominants after an agonistic experience. Neurobiology of Learning and Memory, 87(1), 140-148. 
714

715

716

717

718

719

720

721

722

723

724

725

726

727

728

729

730

731

732

733

734

735

736

737

738

739

740

741

742

743

744

745

746

747

748

749

750

751

752

753

754

755

756

757

758

759

http://doi.org/10.1016/j.nlm.2006.08.002

Kawamura, S. (1958). Matriarchal social ranks in the Minoo-B troop: a study of the rank system of Japanese macaques [in Japanese]. Primates 1:149-156. English translation. In K. Imanishi \& S. A. Altmann (Eds.), Japanese Monkeys: A collection of translations (pp. 105112). Atlanta: Emory University.

Langley, E. J. G., van Horik, J. O., Whiteside, M. A., \& Madden, J. R. (2018a). Group social rank is associated with performance on a spatial learning task. Royal Society Open Science, 1-9. https://doi.org/10.1098/rsos.171475

Langley, E. J. G., van Horik, J. O., Whiteside, M. A., \& Madden, J. R. (2018b). Individuals in larger groups are more successful on spatial discrimination tasks. Animal Behaviour, 142, 87-93. https://doi.org/10.1016/j.anbehav.2018.05.020 0003-3472/Crown

Mateos, C., \& Carranza, J. (1997a). Signals in intra-sexual competition between ring-necked pheasant males. Animal Behaviour, 53, 471-485.

Mateos, C., \& Carranza, J. (1997b). The role of bright plumage in male-male interactions in the ring-necked pheasant. Animal Behaviour, 54, 1205-1214.

Mateos, C., \& Carranza, J. (1999). Effects of male dominance and courtship display on female choice in the ring-necked pheasant. Behavioral Ecology and Sociobiology, 45(3-4), 235244. http://doi.org/10.1007/s002650050558

Mendl, M. (1999). Performing under pressure: stress and cognitive function. Applied Animal Behaviour Science, 65(3), 221-244. http://doi.org/10.1016/S0168-1591(99)00088-X

Nicol, C., \& Pope, S. (1999). The effects of demonstrator social status and prior foraging success on social learning in laying hens. Animal Behaviour, 57(1), 163-171. http://doi.org/10.1006/anbe.1998.0920

Nowicki, S., Searcy, W. A., \& Peters, S. (2002). Brain development, song learning and mate choice in birds: A review and experimental test of the "nutritional stress hypothesis." Journal of Comparative Physiology A: Neuroethology, Sensory, Neural, and Behavioral Physiology, 188(11-12), 1003-1014. http://doi.org/10.1007/s00359-002-0361-3

Oliveira, R. F., McGregor, P. K., \& Latruffe, C. (1998). Know thine enemy: fighting fish gather information from observing conspecific interactions. Proceedings of the Royal Society B: Biological Sciences, 265(1401), 1045-1049. http://doi.org/10.1098/rspb.1998.0397

Popp, J. ., \& DeVore, I. (1979). Aggressive competition and social dominance theory: synopsis. In The great apes (pp. 317-338). Benjamin-Cummings, Reading, Massachusetts.

Pravosudov, V. V., Lavenex, P., \& Omanska, A. (2005). Nutritional deficits during early development affect hippocampal structure and spatial memory later in life. Behavioral Neuroscience, 119(5), 1368-1374. http://doi.org/10.1037/0735-7044.119.5.1368

Pravosudov, V. V, Mendoza, S. P., \& Clayton, N. S. (2003). The relationship between dominance, corticosterone, memory, and food caching in mountain chickadees (Poecile gambeli). Hormones and Behavior, 44(2), 93-102. http://doi.org/10.1016/S0018506X(03)00119-3

Raine, N. E., \& Chittka, L. (2008). The correlation of learning speed and natural foraging success in bumble-bees. Proceedings of the Royal Society B-Biological Sciences, 275(January), 803-808. http://doi.org/10.1098/rspb.2007.1652

Richner, H. (1989). Phenotypic correlates of dominance in carrion crows and their effects on access to food. Animal Behaviour, 38, 606-612.

Ridley, M. W., \& Hill, D. A. (1987). Social-Organization in the Pheasant (Phasianus-Colchicus): Harem Formation, Mate Selection and the Role of Mate Guarding. Journal of Zoology, 
760

761

762

763

764

765

766

767

768

769

770

771

772

773

774

775

776

777

778

779

780

781

782

783

784

785

786

787

788

789

790

791

792

793

794

795

796

797

798

799

800

801

802

803

804

805

211(4), 619-630.

Rowe, C., \& Healy, S. D. (2014). Measuring variation in cognition. Behavioral Ecology, 25(6), 1287-1292. http://doi.org/10.1093/beheco/aru090

Sánchez-Tójar, A., Schroeder, J., \& Farine, D. R. (2017). A practical guide for inferring reliable dominance hierarchies and estimating their uncertainty, 1-37. http://doi.org/10.1101/111146

Sanford, K., \& Clayton, N. S. (2008). Motivation and memory in zebra finch (Taeniopygia guttata) foraging behavior. Animal Cognition, 11(2), 189-198. http://doi.org/10.1007/s10071-007-0106-3

Sapolsky, R. M. (2005). The influence of social hierarchy on primate health. Science (New York, N.Y.), 308(5722), 648-52. http://doi.org/10.1126/science.1106477

Schielzeth, H., Stoffel, M., \& Nakagawa, S. (2017). rptR: Repeatability Estimation for Gaussian and Non-Gaussian Data. https://cran.r-project.org/package $=$ rptR

Searcy, W. A. (1979). Morphological correlates of dominance in captive male red-winged blackbirds. Condor, 81, 417-420.

Sewall, K. B., Soha, J. A., Peters, S., \& Nowicki, S. (2013). Potential trade-off between vocal ornamentation and spatial ability in a songbird. Biology Letters, 9(4), 20130344-20130344. http://doi.org/10.1098/rsbl.2013.0344

Seyfarth, R. M., \& Cheney, D. L. (2002). What are big brains for? Proceedings of the National Academy of Sciences, U.S.A, 99, 4141-4142.

Shaw, R. C., Boogert, N. J., Clayton, N. S., \& Burns, K. C. (2015). Wild psychometrics: evidence for 'general' cognitive performance in wild New Zealand robins, Petroica longipes. Animal Behaviour, 109, 101-111. http://doi.org/10.1016/j.anbehav.2015.08.001

Shettleworth, S. J. (2010). Cognition, Evolution, and Behavior. (Oxford University Press, Ed.). New York.

Spritzer, M. D., Meikle, D. B., \& Solomon, N. G. (2004). The relationship between dominance rank and spatial ability among male meadow voles (Microtus pennsylvanicus). Journal of Comparative Psychology, 118(3), 332-339. http://doi.org/10.1037/0735-7036.118.3.332

Strayer, F. (1976). Learning and imitation as a function of social status in macaque monkeys (Macaca nemestrina). Animal Behaviour, 24(4), 835-848. http://doi.org/10.1016/S00033472(76)80014-0

Taborsky, B., \& Oliveira, R. F. (2012). Social competence: An evolutionary approach. Trends in Ecology and Evolution, 27(12), 679-688. http://doi.org/10.1016/j.tree.2012.09.003

The R Foundation for Statistical Computing. (2017). The R Foundation for Statistical Computing.

Thornton, A., Isden, J., \& Madden, J. R. (2014). Toward wild psychometrics: linking individual cognitive differences to fitness. Behavioral Ecology, 00(00), 1-3. http://doi.org/10.1093/beheco/aru095

Thornton, A., \& Lukas, D. (2012). Individual variation in cognitive performance: developmental and evolutionary perspectives. Philosophical Transactions of the Royal Society of London. Series B, Biological Sciences, 367(1603), 2773-83. http://doi.org/10.1098/rstb.2012.0214

van Horik, J. O., Langley, E. J. G., Whiteside, M. A., \& Madden, J. R. (2016). Differential participation in cognitive tests is driven by personality, sex, body condition and experience. Behavioural Processes, 1-9. http://doi.org/10.1016/j.beproc.2016.07.001

Von Holst, D., Hutzelmeyer, H., Kaetzke, P., Khaschei, M., \& Schönheiter, R. (1999). Social rank, stress, fitness, and life expectancy in wild rabbits. Naturwissenschaften, 86(8), 388- 
806 393. http://doi.org/10.1007/s001140050638

807 Whiteside, M. A., van Horik, J. O., Langley, E. J. G., Beardsworth, C. E., Capstick, L. A., \& 808 Madden, J. R. (2018). Patterns of association at feeder stations for pheasants released into 809 the wild: sexual segregation by space and time. Ibis. http://doi.org/10.1111/ibi.12632

810 Wilson, E. O. (1975). Sociobiology: The New Synthesis. Harvard University Press Cambridge. 811 Wolak, M. E., Fairbairn, D. J., \& Paulsen, Y. R. (2012). Guidelines for Estimating Repeatability. $812 \quad$ Methods in Ecology and Evolution, 3(1), 129-137.

813 Zuk, M., Kim, T., Robinson, S. I., \& Johnsen, T. S. (1998). Parasites influence social rank and 814 morphology, but not mate choice, in female red junglefowl, Gallus gallus. Animal

815 Behaviour, 56(2), 493-499. http://doi.org/10.1006/anbe.1998.0807 


\section{Figure 1}

Timeline of experimental procedures.

Blue birds = known; orange birds = unknown; SG = Social Group condition; $P D=$ Perceived Dominance condition; $\mathrm{N}=$ Total sample size in each condition; $\mathrm{CP}=$ cognitive performance assayed; $\mathrm{D}-\mathrm{D}=$ dominance-display behaviours observed; $\mathrm{Ag}=$ agonistic interactions between males observed; $n=$ sample size of those tested on the spatial discrimination task (these individuals are also highlighted on the figure). 
Week 0 - 10

Captive rearing

$\mathrm{N}=194$

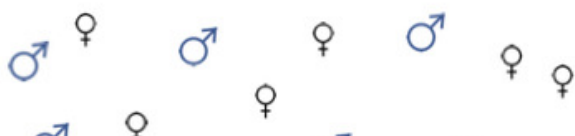

$$
\begin{aligned}
& 0^{x} \quad 0^{x}
\end{aligned}
$$

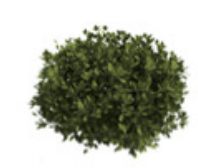<smiles>[18O]</smiles>
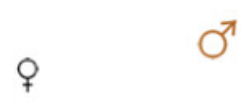

$0^{7}$
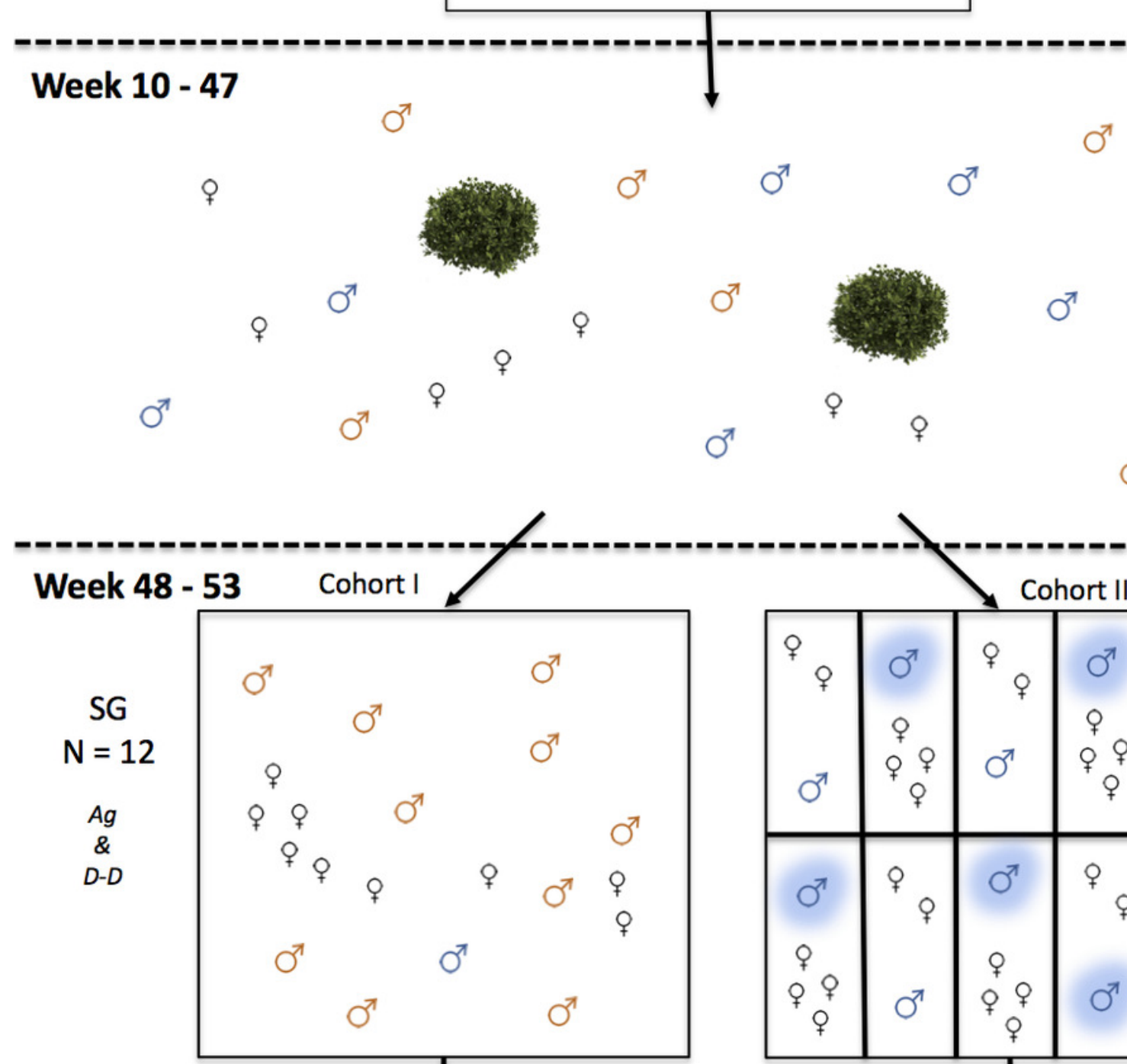

$0^{7}$

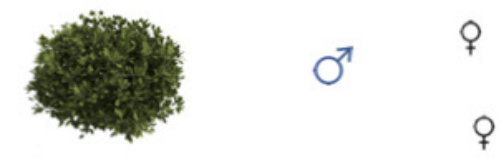

Wild

우

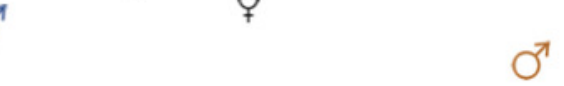

Cohort II

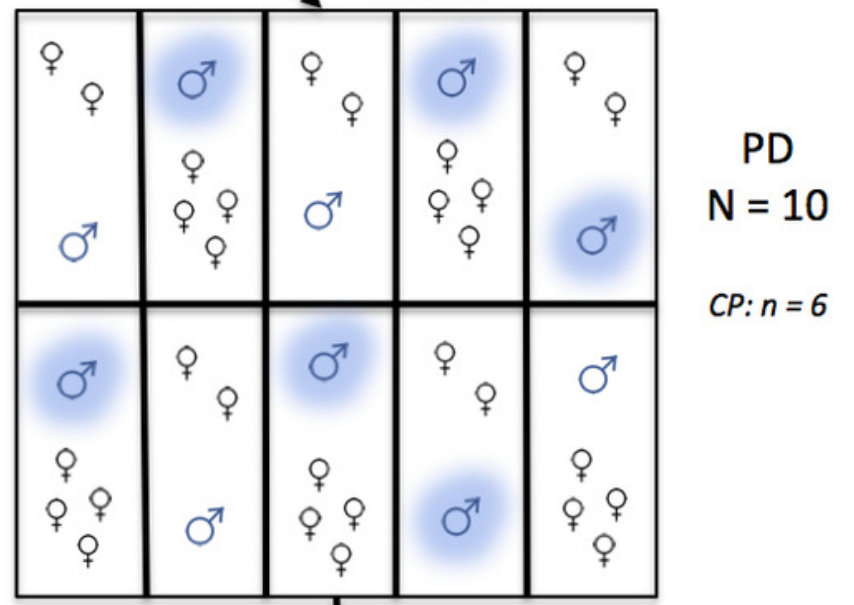

\begin{tabular}{|c|c|c|c|c|c|}
\hline \multirow{3}{*}{$\begin{array}{c}\mathrm{PD} \\
\mathrm{N}=10 \\
C P: n=3 \\
\& \\
D-D\end{array}$} & ${ }^{\circ}$ \% & $\sigma^{\pi}$ & ${ }^{+}$ & & $\overbrace{}^{+}$ \\
\hline & $0^{x}$ & 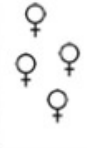 & & 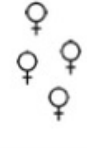 & $\sigma^{7}$ \\
\hline & 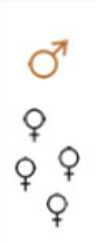 & $\begin{array}{l}{ }_{f} \\
\sigma^{7}\end{array}$ & 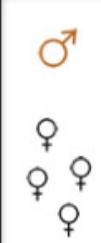 & $\begin{array}{l}q^{\circ} \\
\sigma^{7}\end{array}$ & 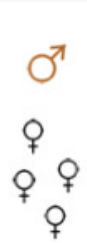 \\
\hline
\end{tabular}

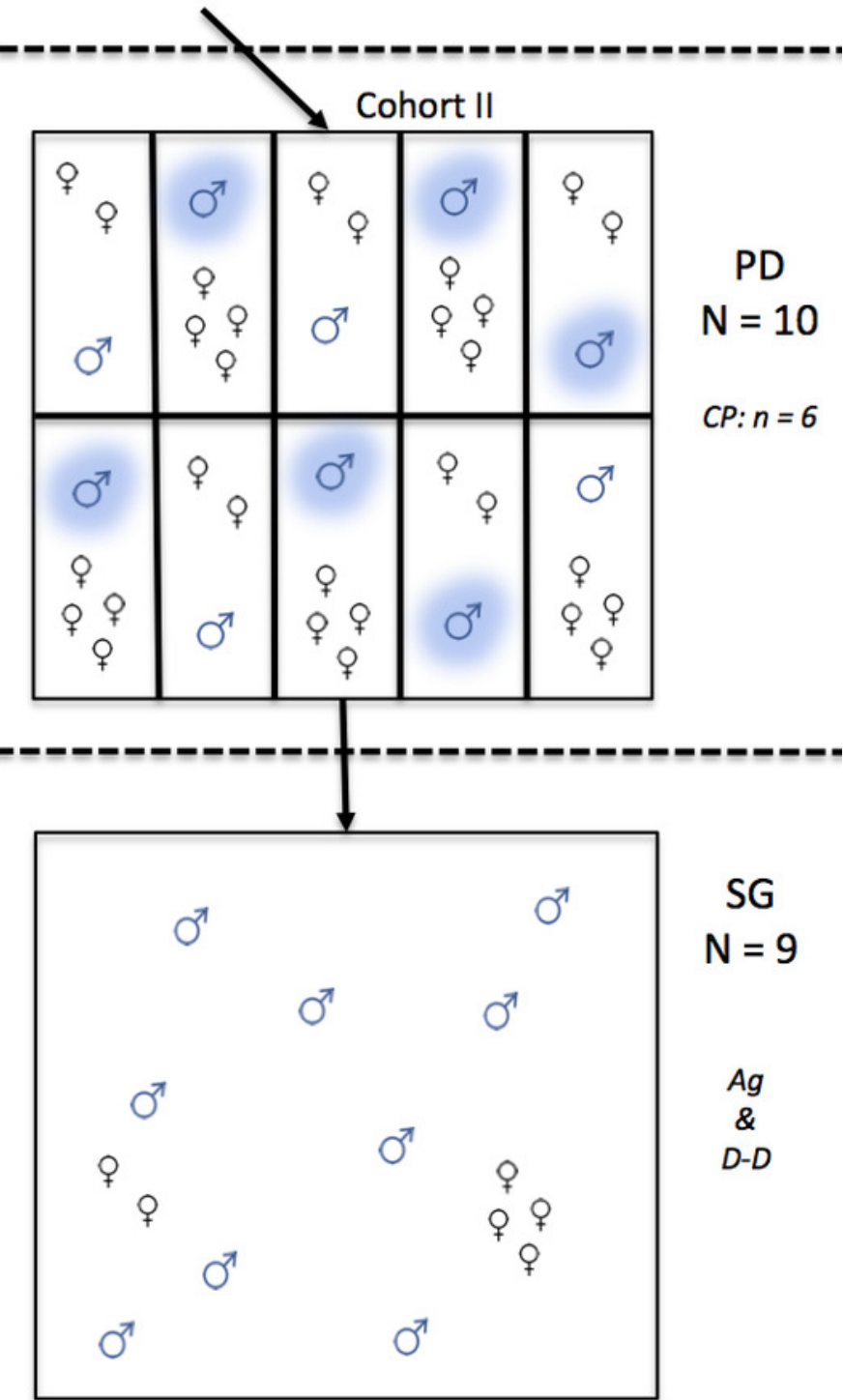


Figure 2

Aerial view of single housing pen of the Perceived Dominance (PD) condition with testing area and test apparatus.

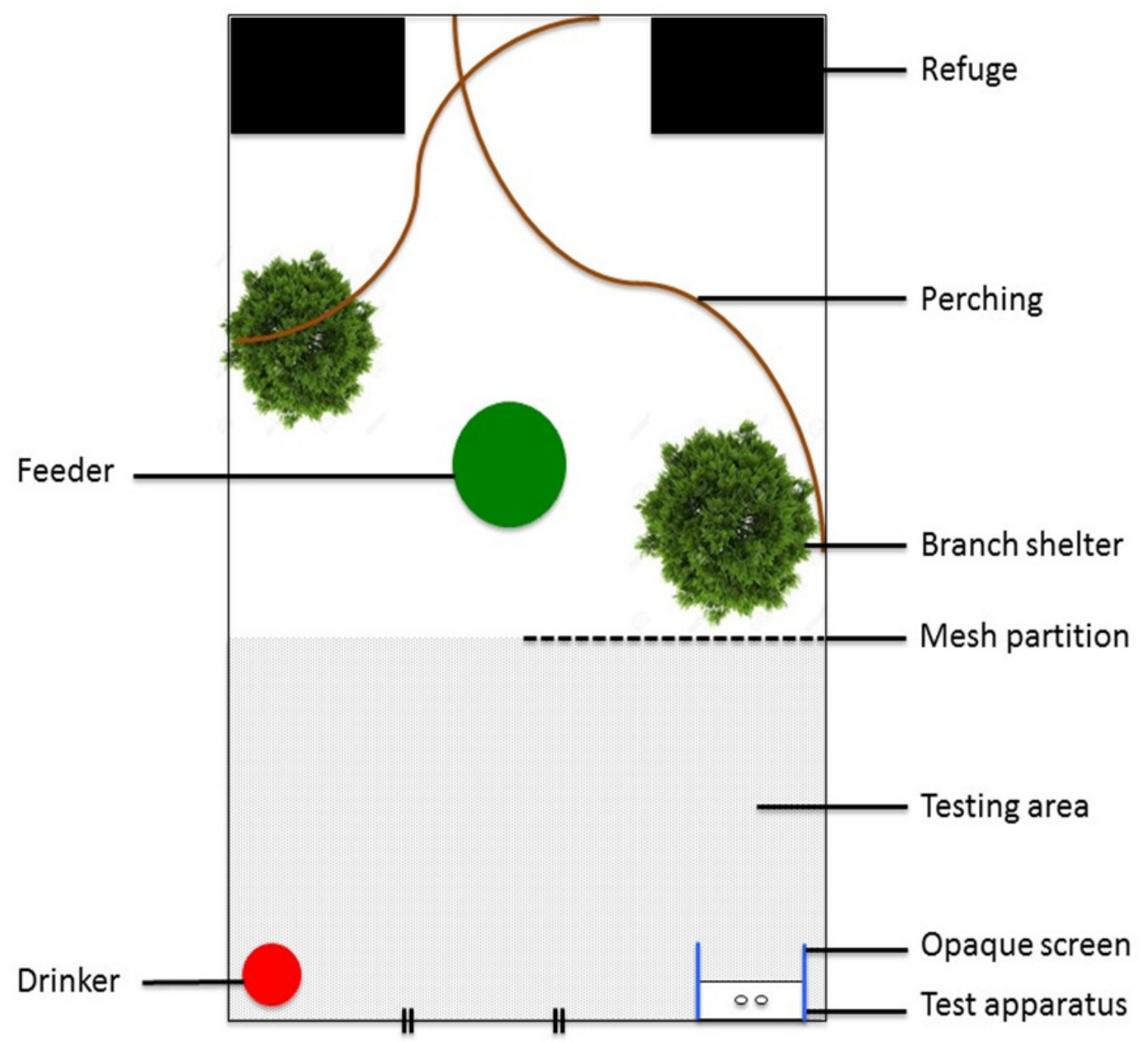




\section{Figure 3 (on next page)}

Relationship between the predicted probability of a correct choice on the final trial ( $X=$ Final) for chick and adult spatial discrimination performances (Cohort II, $\mathrm{n}=6$ ). 


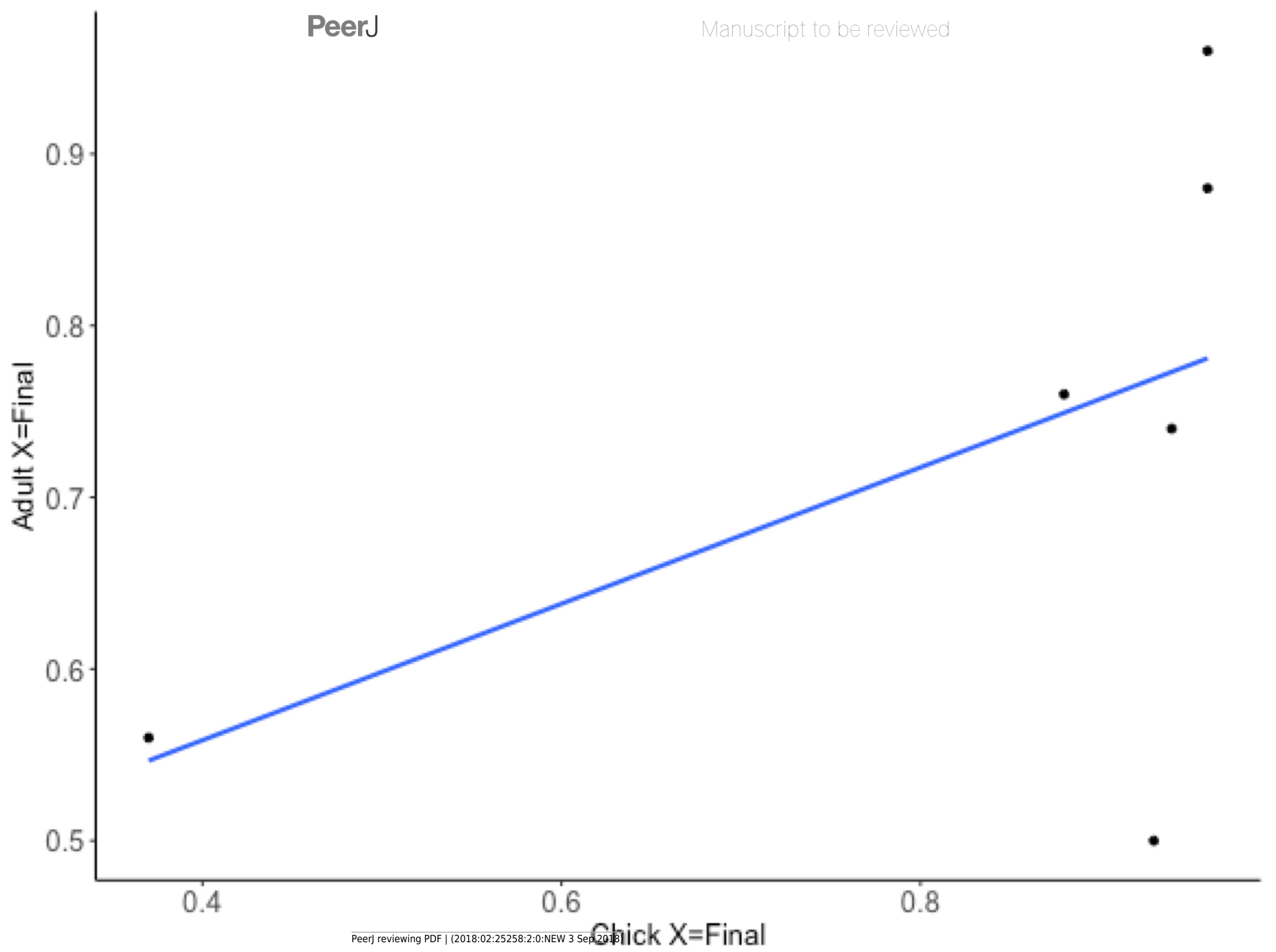


Figure 4

Relationship between predicted trial number when reached a learning criterion of $80 \%$ probability of a correct choice $(\mathrm{Y}=80)$ for chick and adult spatial discrimination performances (Cohort II, $\mathrm{n}=6$ ).

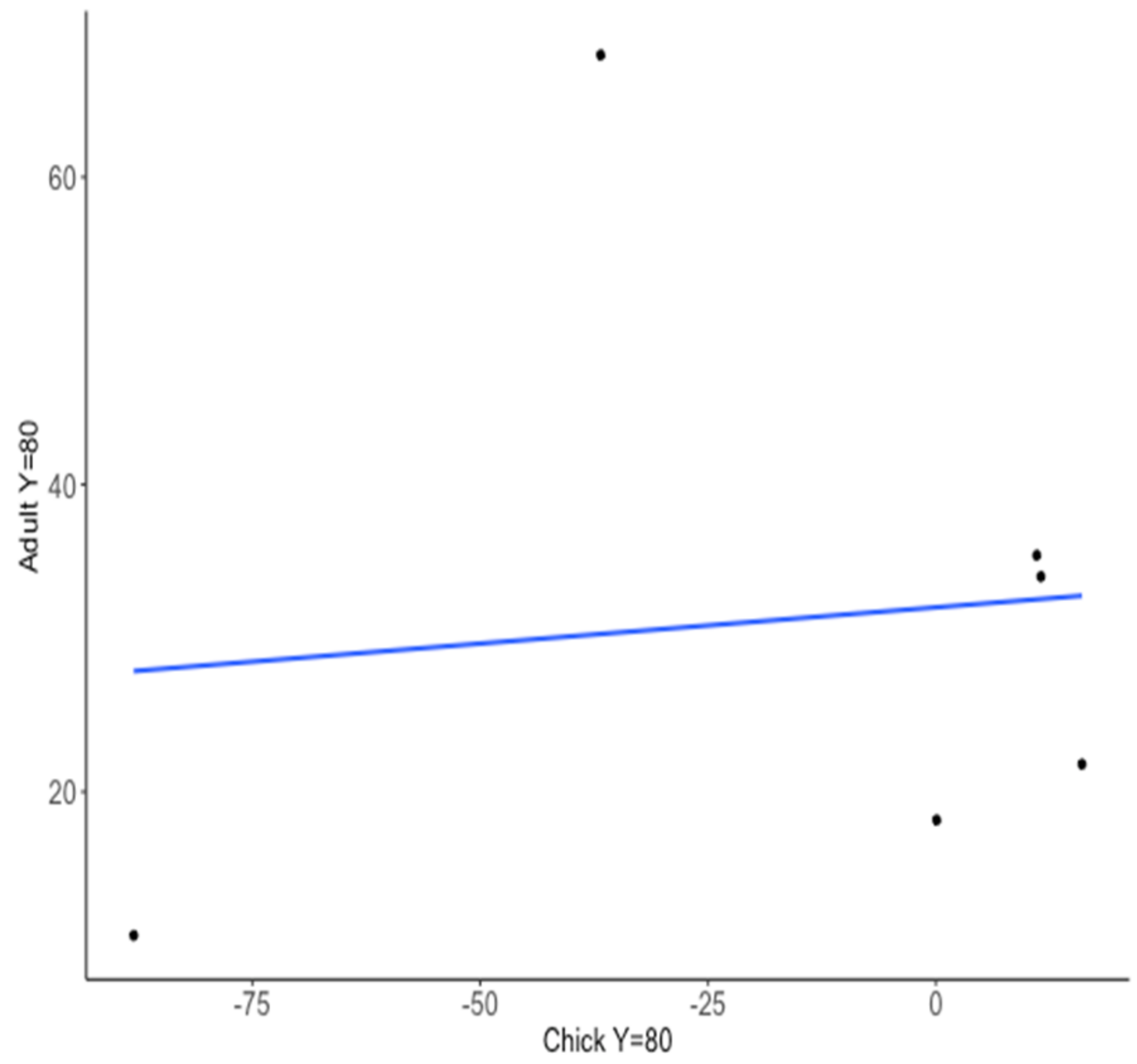


Figure 5

Median rate of crows per hour for 10 males of cohort I was higher when males were housed in the Perceived Dominance (PD) condition then when housed in the Social Group (SG) condition.

The black horizontal line represents the median value. Whiskers represent the lower and upper quartiles (25\% and $75 \%)$.

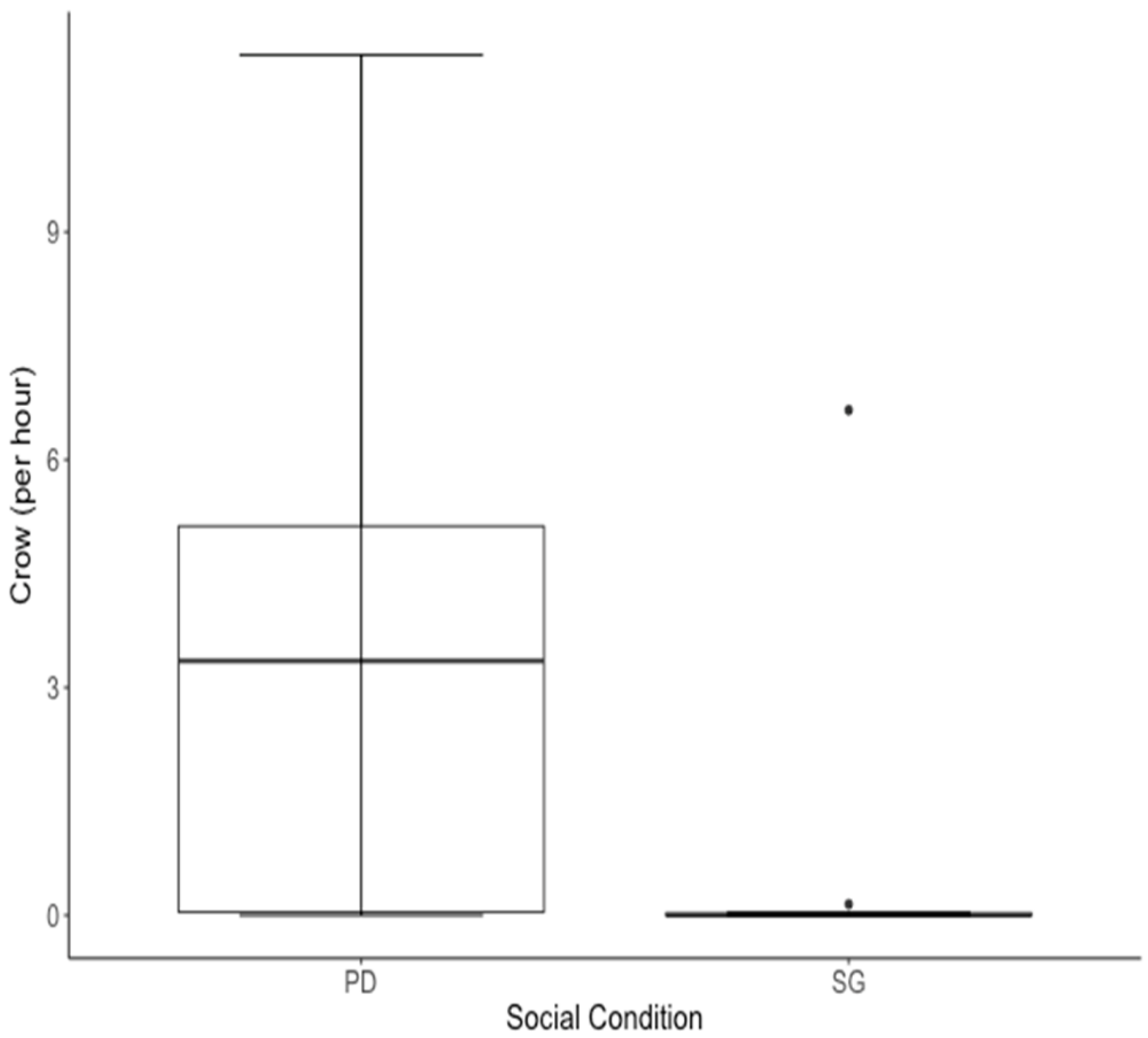


Figure 6

Median rate of lateral struts performed per hour (adjusted for female density) for 10 males of cohort I was higher in the Perceived Dominance (PD) condition compared to the Social Group (SG) condition.

The black horizontal line represents the median value and whiskers represent the lower and upper quartiles (25\% and $75 \%)$.

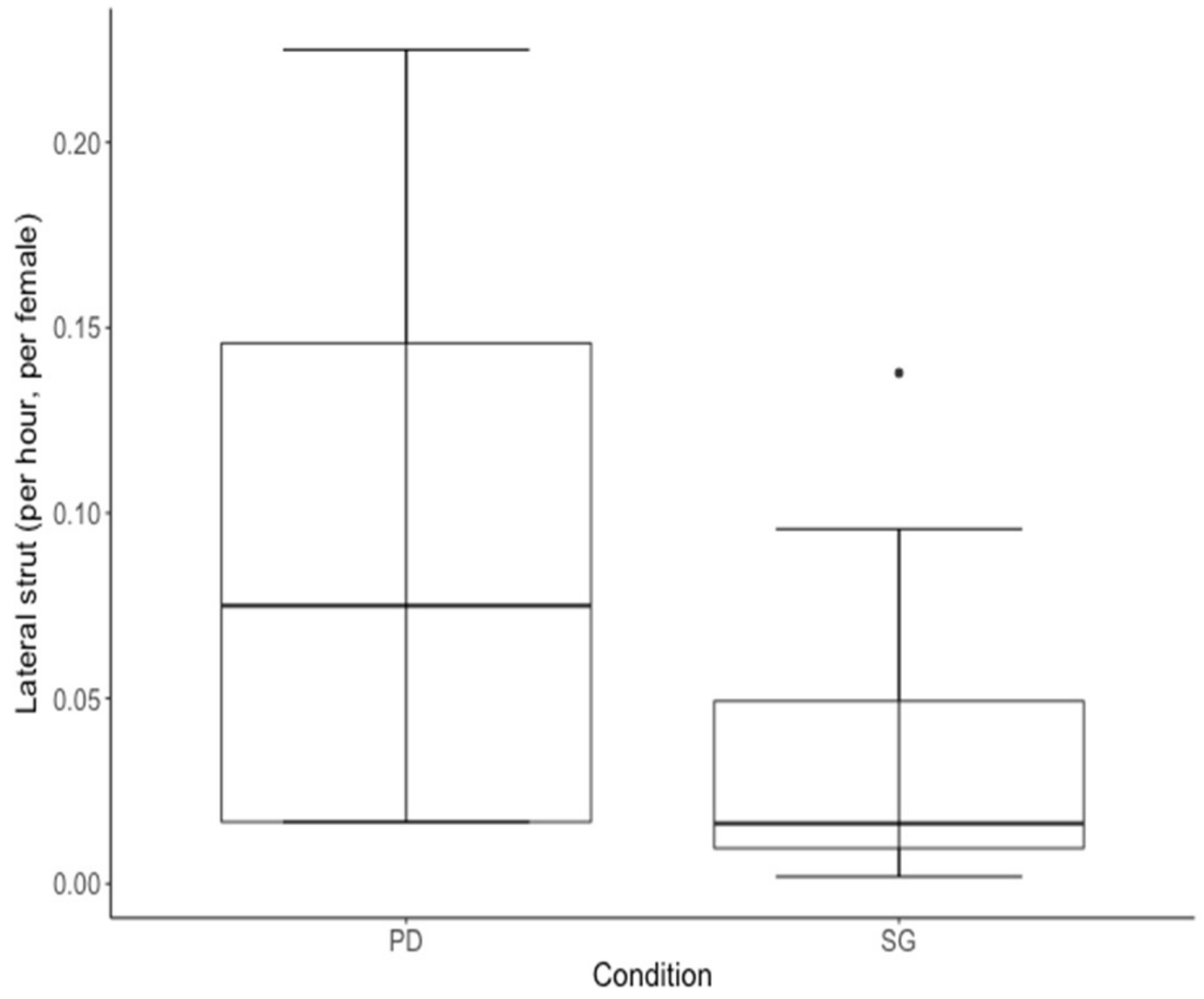




\section{Figure 7}

Predicted probability of choosing correctly on binary spatial discrimination task for adult male pheasants.

Curves predicted from a generalised linear model with social rank included as a factor with three levels, visualized in ggplot2 (Wickham, 2009). Boundaries for high, middle or low rank determined by splitting full range of mean Elo-ratings in to thirds for each cohort. Solid, dashed and dotted lines represent high (Cohort II: $n=2$ ), middle (Cohort I: $n=1$; Cohort II: $n$ $=2$ ) and lowest (Cohort I: $n=2$; Cohort II: $n=1$ ) ranking males, respectively.

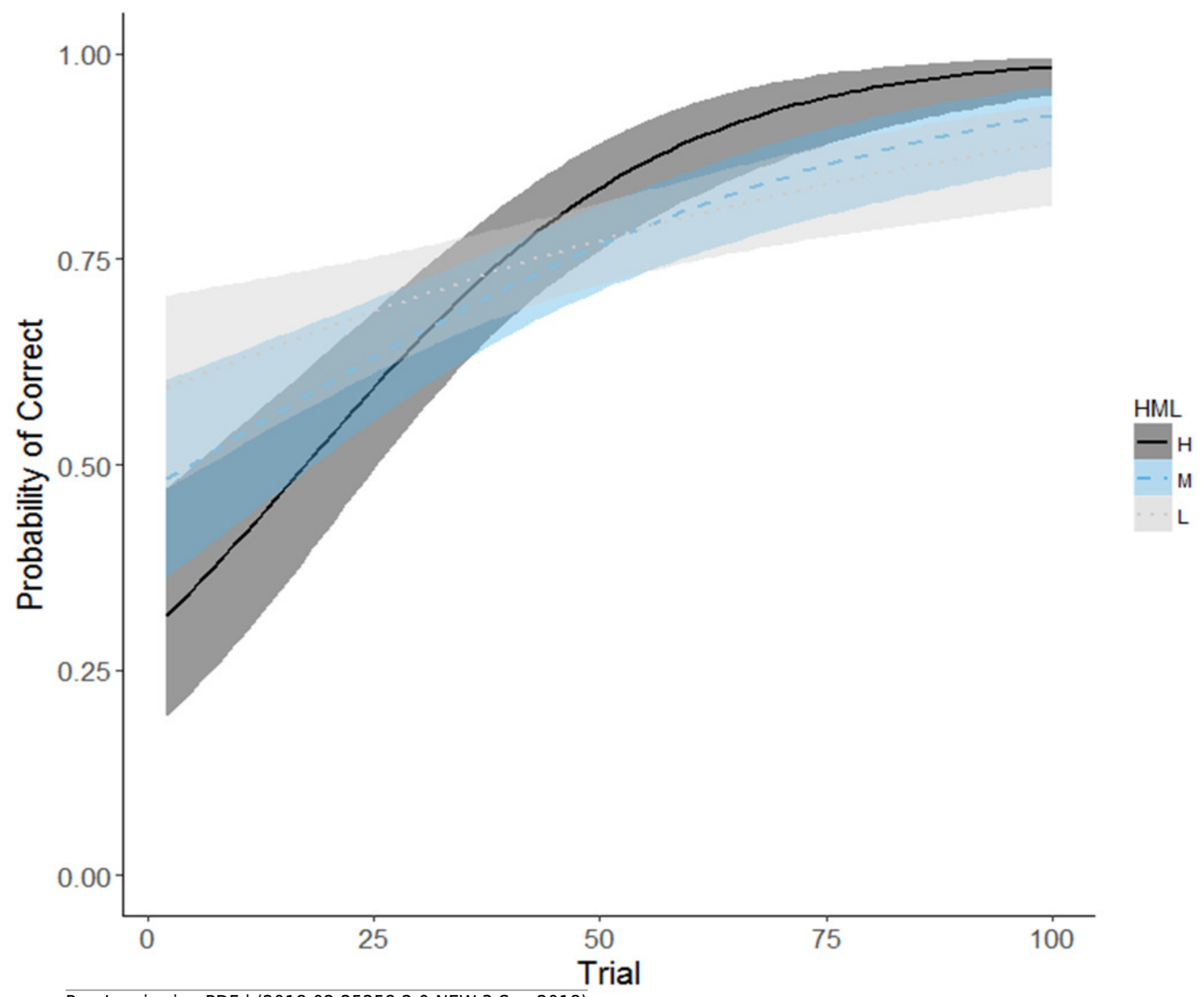




\section{Table $\mathbf{1}$ (on next page)}

Ethogram of agonistic interactions between male pheasants collected during the SG condition for the inference of social rank 
1

\begin{tabular}{ll}
\hline $\begin{array}{l}\text { Agonistic } \\
\text { Chase }\end{array}$ & $\begin{array}{l}\text { aggressor (winner) runs towards opponent and opponent flees (loser) } \\
\text { Threat }\end{array}$ \\
$\begin{array}{l}\text { aggressor (winner) steps forwards and makes a sharp lunge towards } \\
\text { opponent (loser), generally, the opponent flees. Similar to the start of a chase } \\
\text { but aggressor does not continue to run } \\
\text { aggressor (winner) pecks opponent (loser) with the bill, usually directed at } \\
\text { the head, or aggressor (winner) jumps at opponent feet first to direct spurs at } \\
\text { opponent (loser) } \\
\text { Avoid }\end{array} \quad \begin{array}{l}\text { an individual (loser) rapidly changes trajectory while walking and is within } \\
\text { ag of another individual (winner) that is not showing any apparent signs of } \\
\end{array}$
\end{tabular}

2 
Table 2 (on next page)

Ethogram of display behaviours characteristic of dominance collected while pheasants were housed in both the SG and the PD conditions 
1

Lateral strut Male lowers head and flattens one wing toward receiver, sometimes primaries touch the ground while erecting ear tufts and inflating wattle. Tail is spread. Sometimes the display is accompanied with vibration of the tail to create audible sound.

Crow Loud, sudden two-syllable call. Followed by a brief and loud wing flap (Heinz \& Gysel 1970; Cramp \& Simmons 1980)

2

3 


\section{Table 3(on next page)}

Hierarchy statistics for male pheasants of cohort I and II while housed in the social group condition (SG)

$r=$ repeatability estimate for individual Elo-ratings generated from replicated datasets; $r^{2}=$ correlation coefficient from Spearman's Rank Correlation between two halves of split dataset. 
1

\begin{tabular}{lllllc}
\hline$n$ & \multirow{2}{*}{ Cohort } & $\begin{array}{c}\text { No. } \\
\text { interactions }\end{array}$ & $\begin{array}{c}\text { Obs } \\
\text { (days) }\end{array}$ & $r$ & Mean 2.5\% 97.5\% \\
\hline 12 & I & 1044 & 47 & 0.984 & 0.9480 .8810 .993 \\
9 & II & 701 & 14 & 0.996 & 0.9760 .9171 .000 \\
\hline
\end{tabular}

2 


\section{Table 4 (on next page)}

The rate per hour of dominance-display behaviour for male pheasants while housed in each of the two social conditions

The rate per hour of dominance-display behaviour for male pheasants while housed in each

of the two social conditions, in relation to social rank while in the social group condition and the number of females housed with when in the perceived dominance condition. 


\begin{tabular}{|c|c|c|c|c|c|c|c|c|}
\hline & Mean & & & Lateral & & & Crow & \\
\hline Male & Elo-rating & Females & SG & PD & Increase & $\mathrm{SG}$ & PD & Increase \\
\hline 1 & 773.8359 & 2 & 0.138 & 0.1 & -0.038 & 6.655 & 11.333 & 4.679 \\
\hline 2 & 403.1283 & 4 & 0.01 & 0.017 & 0.007 & 0.036 & 4.3 & 4.263 \\
\hline 3 & 385.0008 & 4 & 0.096 & 0.167 & 0.071 & 0.145 & 0.333 & 0.188 \\
\hline 4 & 207.2864 & 2 & 0.013 & 0.017 & 0.003 & 0 & 3.467 & 3.367 \\
\hline 5 & -16.0075 & 2 & 0.019 & 0.017 & -0.002 & 0 & 5.4 & 5.400 \\
\hline 6 & -140.793 & 4 & 0.025 & 0.225 & 0.2 & 0 & 0 & 0 \\
\hline 7 & -302.046 & 2 & 0.006 & 0.133 & 0.128 & 0 & 10.767 & 10.767 \\
\hline 8 & -421.245 & 2 & 0.057 & 0.017 & -0.041 & 0 & 0 & 0 \\
\hline 9 & -601.546 & 4 & 0.002 & 0.15 & 0.148 & 0 & 3.233 & 3.233 \\
\hline 10 & -891.792 & 4 & 0.01 & 0.05 & 0.04 & 0 & 0.067 & 0.067 \\
\hline
\end{tabular}

2 SG = Social Group condition; $P D=$ Perceived Dominance condition; Increase = $(\mathbf{P D}$ rate -

3 SG rate); Lateral strut rate adjusted for female density $=19$ females in the SG condition 4 and 2 or 4 in the PD condition. 


\section{Table 5 (on next page)}

Results from full and minimum adequate model of a generalized linear mixed model

Results from full and minimum adequate model of a generalized linear mixed model fitted on the effects of inferred social rank, cohort, the number of females housed with and trial number on binary spatial discrimination task performances for adult male pheasants tested while in the perceived dominance (PD) social condition. Random intercepts and fixed slopes model. Trial and mean Elo-rating were standardised (z-scores). The table shows model estimates and standard (SE) for each variable with odds ratio (OR) with low (Lo Cl) and high ( $\mathrm{Hi} \mathrm{Cl})$ confidence intervals. 
1

\begin{tabular}{lccccc}
\hline Predictor variable & Estimate & SE & OR & Lo CI & Hi CI \\
\hline Full model & & & & & \\
Cohort & -0.219 & 0.294 & 0.803 & -0.914 & 0.476 \\
Correct on first trial & 0.208 & 0.187 & 1.231 & -0.234 & 0.650 \\
Minimum Adequate model & & & & & \\
Intercept & 0.881 & 0.131 & & & 1.083 \\
Trial & 0.844 & 0.101 & 2.326 & 0.605 & 0.111 \\
Mean Elo-rating & -0.144 & 0.108 & 0.866 & -0.399 & 1.513 \\
Female (4 females) & 1.002 & 0.216 & 2.723 & 0.491 & 0.540 \\
Trial * R Elo-rating & 0.318 & 0.094 & 1.374 & 0.096 &
\end{tabular}




\section{Table 6(on next page)}

Group social rank for adult male pheasants of both cohorts, the number of females they were randomly assigned during the perceived dominance condition (PD) and first choice on a binary spatial discrimination task

Group social rank for adult male pheasants of both cohorts, the number of females they were randomly assigned ( 2 or 4 ) during the perceived dominance condition (PD) and first choice on a binary spatial discrimination task (prior to the opportunity for learning). Males of cohort I were unknown birds that experienced the social group condition (SG) before cognitive testing in the perceived dominance condition (PD). Males of cohort II are known males that experienced these conditions in reverse. 
1

\section{Cohort Rank Females First choice}

$\begin{array}{llll}\text { II } & 2 & 4 & 0 \\ \text { II } & 3 & 4 & 1 \\ \text { II } & 4 & 2 & 0 \\ \text { II } & 5 & 2 & 1 \\ & & & 0 \\ \text { II } & 6 & 4 & 1 \\ \text { I } & 7 & 4 & 0 \\ \text { I } & 10 & 2 & 1 \\ \text { I } & 12 & 2 & \end{array}$

2 